\title{
Anticancer peptide: Physicochemical property, functional aspect and trend in clinical application (Review)
}

\author{
WARARAT CHIANGJONG ${ }^{1}$, SOMCHAI CHUTIPONGTANATE ${ }^{1,2}$ and SURADEJ HONGENG ${ }^{3}$ \\ ${ }^{1}$ Pediatric Translational Research Unit, Department of Pediatrics; ${ }^{2}$ Department of Clinical Epidemiology and Biostatistics; \\ ${ }^{3}$ Division of Hematology and Oncology, Department of Pediatrics, Faculty of Medicine, \\ Ramathibodi Hospital, Mahidol University, Bangkok 10400, Thailand
}

Received February 7, 2020; Accepted June 26, 2020

DOI: 10.3892/ijo.2020.5099

\begin{abstract}
Cancer is currently ineffectively treated using therapeutic drugs, and is also able to resist drug action, resulting in increased side effects following drug treatment. A novel therapeutic strategy against cancer cells is the use of anticancer peptides (ACPs). The physicochemical properties, amino acid composition and the addition of chemical groups on the ACP sequence influences their conformation, net charge and orientation of the secondary structure, leading to an effect on targeting specificity and ACP-cell interaction, as well as peptide penetrating capability, stability and efficacy. ACPs have been developed from both naturally occurring and modified peptides by substituting neutral or anionic amino acid residues with cationic amino acid residues, or by adding a chemical group. The modified peptides lead to an increase in the effectiveness of cancer therapy. Due to this effectiveness, ACPs have recently been improved to form drugs and vaccines, which have sequentially been evaluated in various phases of clinical trials. The development of the ACPs remains focused on generating newly modified ACPs for clinical application in order to decrease the incidence of new cancer cases and decrease the mortality rate. The present review could
\end{abstract}

Correspondence to: Dr Wararat Chiangjong, Pediatric Translational Research Unit, Department of Pediatrics, Faculty of Medicine, Ramathibodi Hospital, Mahidol University, 270 Rama VI Road, Ratchathewi, Bangkok 10400, Thailand

E-mail:wararat_01@yahoo.com

Abbreviations: ACPs, anticancer peptides; AML, acute amyloid leukemia; FSH, follicle stimulating hormone; GHRH, growth hormone-releasing hormone; LHRH, luteinizing hormone-releasing hormone; LONp, lanthanide oxyfluoride nanoparticle; LY6K, lymphocyte antigen 6 complex locus K; PCNA, proliferating cell nuclear antigen; PPV, personalized peptide vaccination; ROS, reactive oxygen species; uPAR, urokinase plasminogen activator receptors; WT1, Wilms' tumor 1

Key words: therapeutic peptide, anticancer peptide, modified peptide, targeting peptide, cancer, clinical application, clinical trial further facilitate the design of ACPs and increase efficacious ACP therapy in the near future.

\section{Contents}

1. Introduction

2. Classification of ACPs

3. Development of therapeutic ACPs

4. Anticancer peptides in clinical trials

5. Future direction

6. Conclusions

\section{Introduction}

Cancer drug therapy was developed from chemotherapy and radiotherapy to molecular targeting therapy combined with a 'guiding missile', for cancer-targeted delivery to avoid healthy tissue damage (1). For example, in genome targeted therapy, DNAs and RNAs can interfere with the normal host genome, and genetic modification is difficult as the modified genes may mutate the original genome or the off-target (2). Furthermore, immunotherapy with antibodies against cancer cell surface antigens can provide specific delivery, but some healthy cells can express the same targeted antigens, resulting in limited effectiveness (3). Small molecules can also exert antitumor effects on cancer cells, such as C188-9, a STAT3 inhibitor, in head and neck squamous cell carcinoma, and GNS561, a lysosomotropic molecule, in intrahepatic cholangiocarcinoma $(4,5)$. Moreover, these small molecules can be used in drug delivery systems (6); however, they are difficult to synthesize. Therefore, peptides against cancer cells are an alternative therapeutic method in anticancer drug development.

Anticancer peptides (ACPs): What and why? ACPs, as small peptides containing amino acid sequences, are selective and toxic to cancer cells (7). ACPs are a superior choice of therapeutics compared with antibodies and small molecules due to their high selectivity, high penetration and easy modifications (8-10). Ideally, anticancer therapy should destroy a range of cancer types, but not all healthy cells. 
A different property between cancerous and healthy cells is the cell membrane. Numerous anticancer peptides destroy cancer cells via apoptosis and necrosis by membrane lysis or pore formation (11-13). The eukaryotic cell membrane contains cholesterol to protect lytic action by modifying membrane fluidity (14). Moreover, a high level of membrane cholesterol can inhibit lytic activity. It has been shown that membrane fluidity of cancer cells is higher compared with healthy cells (15). Cancer cells also contain more abundant microvilli compared with healthy cells, which increases the cell surface area (16). Furthermore, healthy cells have electrical neutrality, whereas cancer cells contain a negatively charge component on their surface (17), leading to membrane destabilization, cytotoxicity and cancer cell lysis when interacting with small molecules, such as ACPs $(18,19)$. In addition, the primary driving force for the interactions between peptides and the healthy cell membrane is the hydrophobic interactions, while that between peptides and the cancer cell membrane is the electrostatic interactions (20).

Anticancer medicines contain molecularly targeted drugs with or without 'guiding missiles' to interact with specific molecular targets on cancer cells (21). Besides molecularly targeted drugs, drug-delivery to the cancer cell surface was developed using the most important properties, including high specificity, high selectivity and the binding capability to various targeted drugs, as well as being easy to synthesize and produce (21). Peptide properties can be used both in molecularly targeted drugs and 'guiding missiles' to inhibit cell proliferation or eradicate cancer cells completely, depending on the amino acid residue composition, sequence length, isoelectric point, molecular weight, net charge, hydrophobicity, amphiphilicity, secondary structure and structural orientation (22). These ideal anticancer peptide characteristics are summarized in Fig. 1. Membrane characteristics promote or inhibit drug penetration, drug conformation and/or location within the membrane and sequentially affect therapeutic targets (23). Healthy cell membranes have zwitterion phosphatidylcholine and sphingomyelin in an outer leaflet and anionic phosphatidylserine and the phosphatidylethanonlamine in the inner leaflet with the asymmetric distribution (24). The inner leaflet with the asymmetric distribution is primarily maintained by flippases (phosphatidylserine and phosphatidylethanonlamine from outer to inner membrane), floppases (phosphatidylcholine and cholesterol from inner to outer membrane) and scramblases (facilitated the flip-flop of lipids) $(24,25)$. In contrast, the cancer cell membrane loses this asymmetric distribution and alterations in membrane fluidity, resulting in exposure of negative charge of phosphatidylserine on the surface of the membrane, as well as the locating of phosphatidylethanonlamine on the outer leaflet (26-28). Furthermore, sphingomyelin is decreased in the cancer cell membrane and is associated with tumorigenesis (29). Different lipid composition affects membrane fluidity, influencing drug penetration and biological action $(30,31)$. Extracellular acidity with or without exosome release affects the $\mathrm{pH}$, changing from 7.4 to 6.5 (typical $\mathrm{pH}$ of cancer), forming the malignant tumor phenotype (32). The surrounding environment in the acidic extracellular $\mathrm{pH}(\mathrm{pHe})$ can promote cancer invasiveness (33). Specific interaction between anticancer peptides and cell membrane components are mostly bound by electrostatic interactions (34).
Anticancer peptides act as either molecularly targeted peptides, which can penetrate and directly bind to the specific cancer cell or organelle membranes, or binding peptides linking to the anticancer drugs (35-37). In cancer cells, anticancer peptides, as molecular targeting peptides, particularly in the $\alpha$-helical form, penetrate the plasma membrane, the nuclear membrane and/or the mitochondrial membrane exerting pharmacological activity via different mechanisms (such as the inhibition of DNA synthesis or cell division), thus promoting cancer cell apoptosis (38-41). However, binding peptides, also referred to as cancer-targeting peptides or cell-penetrating peptides, that have no anticancer property, can recognize and penetrate the cancer cell membrane (42). Binding peptides can also be used for drug delivery by binding to the anticancer drugs, such as those that are non-penetrable (43).

Amino acid composition and derivatives in peptides also convey anticancer properties. Amino acid residues containing peptides can drive cell permeability (44-46). The amino acid residues that are predominant in peptides with anticancer abilities include glycine, lysine and leucine (47). For example, hydrophobic positively charged lysine- and arginine-rich peptides act as cationic peptides that can interact with membranes via a snorkeling mechanism, including selecting anionic membranes on cancer cells, disrupting cell membrane integrity, penetrating into the membrane and potentially serving a role in cancer cell toxicity (48). Moreover, protonation of histidine under acidic $\mathrm{pH}$ conditions means that histidine-containing peptides can induce cancer cytotoxicity via membrane permeability under acidic conditions $(49,50)$. Glutamic and aspartic acid residues present potential anti-proliferative activity on the tumor cells (51). Cysteine residues in ACPs do not serve a role in the selectivity and toxicity for cancer cells, but cysteine-rich domains on a number of cell surface receptors can stabilize and maintain extracellular motif or domain structures (52).

Internal prolines in peptides are crucial for membrane interaction and conformational flexibility, which is the same as glycine residues (53). It has been reported that serine and glycine-free diets can slow tumor growth and enhance antiproliferative effects (54). Methionine, a moderately hydrophobic amino acid, does not serve a major role in ACPs, but its elevated levels can be consumed by cancer cells. Furthermore, a methionine-deficient diet causes a metabolic defect in cancer cells by arresting cancer cell proliferation (55). Phenylalanine, a strongly hydrophobic residue, is highly present in primary tumors and acts as a protective amino acid (56). Phenylalanine-containing peptides can also enhance the affinity for targeting the cancer cell membrane (57). Tyrosine and tryptophan are weakly hydrophobic amino acids; tyrosine does not serve a role in toxicity of ACPs, whereas tryptophan may exert a role in the toxicity of some ACPs against cancer cells such as indolicidin and trans-activator of transportation (TAT)-Ras GTPase-activating protein-326 peptides $(19,58,59)$. However, synthesized peptides containing tryptophan and histidine may decrease cytotoxicity, while those containing tyrosine, phenylalanine or proline may be able to increase cytotoxic activity (60). The tryptophan position on the cell-penetrating peptides serves an important role in entering cancer cells, which subsequently involves an 

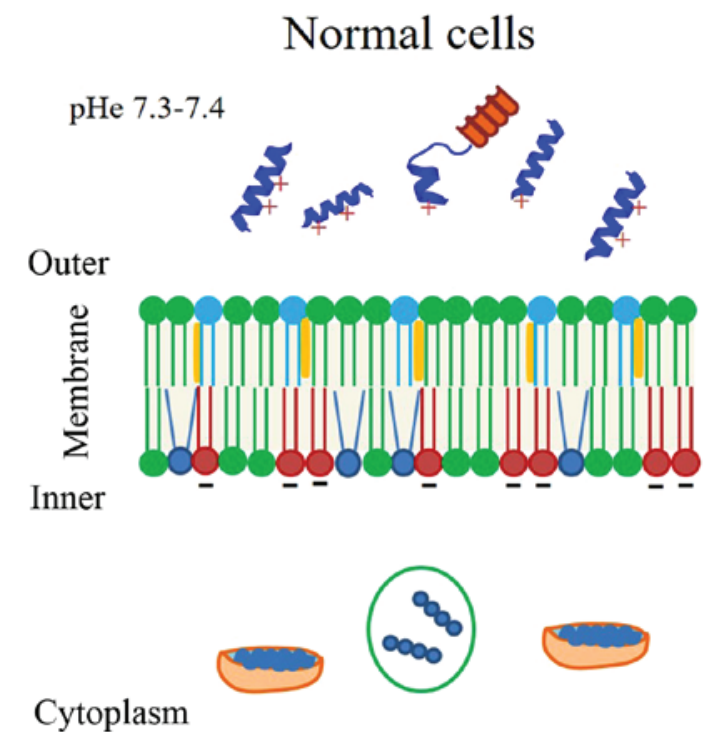

\section{Cancer cells}

pHe 6.2-6.9

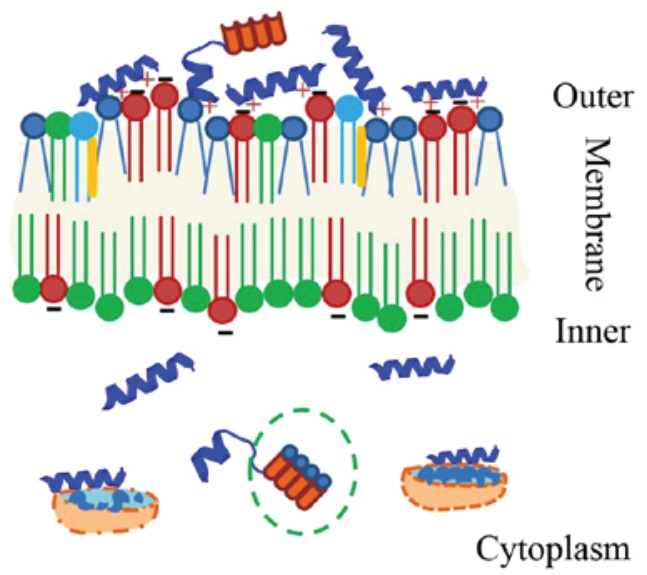

Cytoplasm
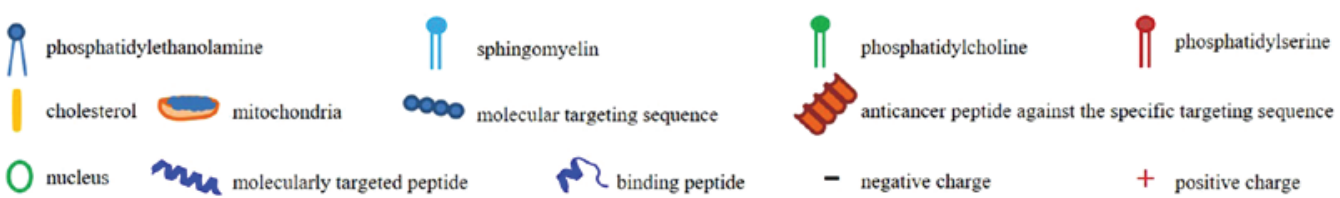

Figure 1. Comparisons of membrane characteristics and anticancer peptides action on healthy cells (left) and cancer cells (right). The outer leaflet of the healthy cell membrane presents a neutral net charge leading to non-interaction of anticancer peptides on the healthy cell surface (left), whereas negative net charge on the outer leaflet of the cancer cell membrane could interact with the cationic anticancer peptides (right). In cancer cells, anticancer peptides, particularly in the $\alpha$-helical form, act as molecularly targeted peptides that can penetrate and directly bind to the specific cancer cell or organelle membranes promoting cancer cell apoptosis. While, binding peptides linking to the anticancer drugs that have no anticancer property, can recognize and penetrate the cancer cell membrane. pHe, extracellular $\mathrm{pH}$.

endocytic pathway and binding at the major groove of nuclear DNA (61). The role of amino acid residues on ACPs and on cancer cells is summarized in Table I. Collectively, these findings suggested ACPs should contain cationic and hydrophobic amino acid residues to further form secondary structures that affect cancer cells.

$A C P s$ and the structure-activity relationship (SAR). The association between ACPs and SAR has been investigated and analyzed using machine learning, and it has been demonstrated that the majority of ACPs contained 21-30 amino acids and were predominately composed of glycine, lysine and leucine (47). In addition, amino acid residues on a peptide influences its anticancer activity depending on the cationic, hydrophobic and amphiphilic properties associated with forming helical structure (62-64). Anticancer activity is primarily determined by the $\mathrm{IC}_{50}$ value associated with cancer cell membrane disruption (62). It has been reported that peptides with a higher hydrophobicity can penetrate into the hydrophobic core of the cancer cell membrane, resulting in cancer cell disruption via necrosis (62). Several studies have aimed to substitute low hydrophobic and neutral or acidic amino acid residues with positively charged amino acid residues, such as lysine and leucine, on the polar and non-polar faces of $\alpha$-helical peptides $(63,65)$. As a result, high cationic peptides with moderate hydrophobicity can enhance the cytotoxicity of cancer cells (63). Peptides in free-form do not fold in solution, but arrange in an $\alpha$-helix or $\beta$-sheet via electrostatic interaction on the membrane surface of the cells (11).

As well as the physicochemical properties, the secondary structure of the peptides is important in cell surface interaction, such as peptide structural orientation (57). The orientation of peptides can enhance the surface-activity for targeted interaction with the cancer cell membrane (66). The angle of the interaction leads to destabilized lipid packing on the cancer cell membrane, thus resulting in membrane penetration (67). Furthermore, modifying peptides by adding chemical groups, including methylation, acetylation or phosphorylation (particularly phosphorylation at tyrosine), can inhibit STAT3 phosphorylation, leading to cancer cell death (68). The potential modification of natural peptides is presented in Fig. 2. Therefore, the results indicated that the secondary structure of ACPs serves a crucial role in peptide-cancer cell membrane interaction, leading to cancer cell disruption and cell death.

\section{Classification of ACPs}

Anticancer peptide creation should consider the peptide structure, mode of action, selectivity and efficacy to specific cancer cells $(69,70)$. In the present review, active peptides were classified into three types depending on their actions, including: i) Molecularly targeted peptides, which directly act on cancer cells via cytotoxic, anti-proliferative and apoptotic activities; ii) 'guiding missile' peptides or binding peptides, which are drug binding peptides used for transporting drugs 
Table I. Role of amino acid residues on ACP effects in cancer cells, based on previous reports.

\begin{tabular}{|c|c|c|c|}
\hline Amino acid residue & Amino acid properties & Action on cancer cells & (Refs.) \\
\hline \multicolumn{4}{|c|}{ Charged residues on ACPs } \\
\hline Lysine & Positively charged & Disrupt cell membrane integrity and penetrate cell & $(48)$ \\
\hline Arginine & (basic amino acids), & membrane, leading to cancer cell cytotoxicity & \\
\hline Histidine & polar, hydrophilic & $\begin{array}{l}\text { Induce cancer cytotoxicity via membrane permeability } \\
\text { under acidic condition }\end{array}$ & $(49,50)$ \\
\hline $\begin{array}{l}\text { Glutamic acid } \\
\text { Aspartic acid }\end{array}$ & $\begin{array}{l}\text { Negatively charged } \\
\text { (acidic amino acids), } \\
\text { polar, hydrophilic }\end{array}$ & Antiproliferative activity on tumor cells & $(51)$ \\
\hline \multicolumn{4}{|c|}{ Effect on cancer cell structure } \\
\hline Cysteine & Polar, non-charged & $\begin{array}{l}\text { On numerous cell surface receptors for stabilizing and } \\
\text { maintaining extracellular motif/domain structure }\end{array}$ & $(52)$ \\
\hline Proline & $\begin{array}{l}\text { Non-polar, aliphatic } \\
\text { residues }\end{array}$ & $\begin{array}{l}\text { Membrane interaction and conformational flexibility, } \\
\text { may be able to increase cytotoxic activity }\end{array}$ & $(53,60)$ \\
\hline Glycine & & Membrane interaction and conformational flexibility & $(53)$ \\
\hline Phenylalanine & Aromatic & $\begin{array}{l}\text { Enhance the affinity for target cancer cell membrane, } \\
\text { act as protective amino acids of primary tumors and } \\
\text { may be able to increase cytotoxic activity }\end{array}$ & $(57,60)$ \\
\hline \multicolumn{4}{|c|}{ Effect on cancer cell metabolism } \\
\hline Methionine & Polar, non-charged & Reduced methionine will arrest cancer cell proliferation & $(55)$ \\
\hline Tyrosine & Aromatic & May be able to increase cytotoxic activity & $(60)$ \\
\hline Tryptophan & & $\begin{array}{l}\text { Serve a role in the toxicity of some ACPs to cancer cells, } \\
\text { entering cancer cells following an endocytic pathway } \\
\text { and then binding at the major groove of nuclear DNA }\end{array}$ & $(19,61)$ \\
\hline
\end{tabular}

ACP, anticancer peptides.

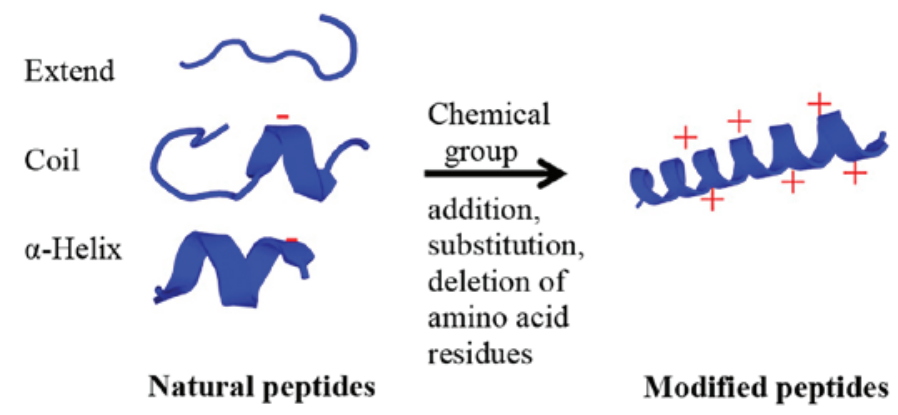

Figure 2. Modification of natural peptides. The natural peptide conformations included the extended, the coiled and/or the $\alpha$-helical forms with neutral, anionic or cationic properties. These natural peptides are modified by adding the chemical groups (such as acyl and methyl groups) or the positive amino acid residues (such as lysine and arginine) to increase positive net charge and specificity for cancer cell targets. Moreover, the addition, deletion or substitution of the amino acid residues changes the conformation from the extended or coiled peptides to the $\alpha$-helix form for higher cancer cell penetration. After modification, the cationic $\alpha$-helix modified peptide exhibits higher efficacy and specificity to the cancer cells.

into the cancer cell targets; and iii) cell-stimulating peptides that indirectly effect other stimulating cells to kill cancer cells, such as via immunomodulatory activities and hormone receptors (71-73).

Molecularly targeted peptides. Molecularly targeted peptides, which are specific to the cancer cell targets, can penetrate, bind and then inhibit or kill cancer cells that are in an important stage of carcinogenesis or proliferation (74). The peptides concerning target cells can be classified into two major groups, including: i) Peptides against only cancer cells, and not against healthy cells $(75,76)$ and, ii) peptides against both cancerous and healthy cells (77). Numerous peptides have selectivity for cancer cells but not healthy cells, such as peptides derived from defensins, lactoferricin B, cecropins, magainin-2 and chrysophsin-1 (22).

The majority of ACPs are collected using the CancerPPD resource for predicting peptide structure and identifying the best ACP for further study (7). In addition, ACPs are identified via computational methods that consider amino acid composition, binary profiles and sequence-based methods (78-80). 
Membranolytic ACPs are generated de novo using automated designs based on $\alpha$-helical cationic amphipathic peptide sequences against the cancer cells (81). Anionic molecules in the malignant cells conferring a net negative charge are different from the normal mammalian cell membrane, which have a neutral net charge (17). High cholesterol contents in healthy cells can obstruct the cationic peptide entry via cell fluidity; healthy cells are less fluid compared with cancer cells $(15,82)$. Furthermore, peptides can permeate into the cells, causing mitochondrial swelling with cytochrome c release, followed by apoptosis (83). For example, Mastoparan I, a peptide with a $\alpha$-helical structure, can act on the negative charge of prostate and liver cancer cell surfaces causing cell injury, cell swelling, cell bursting and then necrosis (84). Moreover, SVS-1 (KVKVKVKV ${ }^{\mathrm{D}}{ }^{\mathrm{L}} \mathrm{PTKVKVKVK- \textrm {NH } _ { 2 }}$ ), as a $\beta$-sheet structure, disrupts cell membranes via pore formation in lung-, epidermal- and breast-cancer cells $(85,86)$. Peptides extracted from marine organisms, such as sponges, mollusks, tunicates, bryozoans, algae, fish, soft corals and sea slugs, can act against human cancer cells via, for example, anti-proliferative, cytotoxicity and anti-tubulin activities, as well as suppressing microtubule depolymerization (87).

Amino acid composition of the peptides can act directly against various cancer cell types. For example, highly cationic peptides can enhance cancer cell specificity, while an increase in hydrophobic peptides can decrease the degree of specificity (63). Moreover, polycationic peptides have selectivity against human acute T-cell leukemia via a higher membrane potential compared with healthy cells (88). Lysine and arginine-rich peptides with an intact amphipathic helical interface can also enhance cell lysis via membrane lysis mechanisms by penetrating and inducing caspase-3-dependent apoptotic cell death (89). The methods of peptide designing, such as cyclization, hybridization, fragmentation and modification, have potential advantages in increasing drug half-life time in plasma, enhancing stability and activity and decreasing toxicity of ACPS, for improving their therapeutic efficacy (90).

Therapeutic peptides are classified into three classes based on the mechanism of peptide entry into cancer cells, including: i) Pore-forming peptides, which bind to negatively charged molecules on the cancer cell membrane for inducing apoptosis or necrosis; ii) cell-penetrating peptides, which translocate across the plasma membrane and transporting small molecules to oligonucleotides or proteins, known as internalization; and iii) tumor-targeting peptides, which bind to receptors on the cancer cell surface for cell internalization (91). Based on the mechanism of entry, therapeutic peptides are also classified into three groups based on their biological targets, including: i) Signal transduction pathways; ii) cell cycle regulation; and iii) cell death pathways $(92,93)$. For instance, a tumor-penetrating peptide, KLA, exerts pro-apoptotic activity, which disrupts the mitochondrial membrane, leading to programmed cell death in tumors (40). In a tumor suppressor mechanism, kisspeptin-1 metastasis suppressor, a precursor for several shorter peptides, which regularly exhibits decreased expression in metastatic tumors, can suppress colonization of disseminated cancer cells in distant organs and is involved in mechanisms of tumor angiogenesis, autophagy and apoptosis regulation in breast cancer (94). Furthermore, the tubulysin analogue KEMTUB10 can inhibit tubulin polymerization during mammalian cancer cell proliferation, block the $\mathrm{G}_{2} / \mathrm{M}$ phase of the cell cycle and stimulate apoptosis or cell death via p53, Bcl-2-interacting mediator of cell death and Bcl-2 (95). Although ACPs can induce cancer cell death and specify an expressed molecule to cellular targets, such as a cationic anticancer peptide, temporin-1CEa and melanoma cell surface-expressed phosphatidylserine (96), ACPs have limitations, including drug binding peptide delivery to cancer cell targets (97). Thus, ACPs could be developed for their high penetration into the tumor tissue and tumor cells, as well as high antitumor activity (40). While ACPs can progress from binding to killing cancer cells, in terms of molecular targeting peptides, ACPs cannot be specific or penetrated all cancer cell types, leading to the need for an addition of a binding cancer cell target, such as 'guiding missile' peptides or binding peptides.

'Guiding missile' peptides or binding peptides. Optimizing anticancer drug delivery requires the safety of healthy cells, as well as cancer cell elimination (98). 'Guiding missile' peptides or binding peptides, used as delivery carriers, should hold the poorly stable, non-soluble drugs and control drug-release inside the tumor environments (99). Furthermore, these peptides require specificity, affinity and dose effectiveness (98). Anticancer drug concentration is continually diluted during transport until reaching the target areas. However, drug binding adjuvant and nanoparticles can retain drug concentration during transport to target areas and induce the slow-release of the drug at these target areas $(100,101)$.

Drug concentration and cell and tissue barriers are an obstacle for therapeutic efficacy. Medical application for drug delivery requires biologically active conjugates (cargoes) and/or binding peptides ('guiding missile') to reach specific intracellular targets (102-104). Minimal amino acid sequences of various cell-penetrating peptides, typically comprising 5-30 amino acid residues, especially cationic residues, can pass through tissue and cell membranes using energy-dependent or -independent mechanisms without the interaction of specific receptors (36). Binding peptides can bind to the cargoes with either covalent (mainly disulfide and thioester bonds) or non-covalent bonds (electrostatic and/or hydrophobic interactions between negatively charged cargoes and positively charged peptides) to protect the cargoes from enzymatic degradation (105).

The physical and chemical properties of binding peptides can be categorized into three main classes: Cationic, amphipathic and hydrophobic peptides (42). Firstly, cationic peptides contain highly positive net charges comprising lysines and arginines. Arginine contains a guanidine head group, which is used to form bidentate hydrogen bonds with the negatively charged carboxylic, sulfate and phosphate groups on the cell membrane, resulting in binding peptide internalization into the cells; however, lysine does not contain the guanidine head group, leading to lower penetration into the cell membrane (106). Secondly, amphipathic peptides, which contain both hydrophilic and hydrophobic amino acids, are classified into primary (covalent binding hydrophobic domain targeting to cell membrane and nuclear localization signal), secondary ( $\alpha$-helical structure with hydrophilic and hydrophobic residues on different sides of the helix or $\beta$-sheet for cellular internalization) and proline-rich (pyrolidine ring without hydrogen bonds on $\alpha$-amino group able to allow 
cell permeability) peptides $(107,108)$. Hydrophobic peptides contain non-polar amino acids with a low net charge and have a high affinity for the hydrophobic domain of the cell membrane, leading to cellular internalization and translocation across the membrane via energy-independent mechanisms $(107,109)$.

Binding peptides enter target cells via cell penetration (pore formation and membrane destabilization) and endocytosis (macropinocytosis, clathrin or caveolin-mediated endocytosis, and clathrin/caveolin-independent endocytosis with enhanced endosomal escape from a lysosome) depending on physicochemical properties, size and concentration of the peptides (110). There are various mechanistic studies examining binding peptides depending on their targets. For example, D-form octaarginines stimulates the intestinal epithelial transport of drugs, such as insulin, via energy-independent unsaturable internalization (111). Furthermore, a specific peptide derived from nuclear localization signal (NLS) and epidermal growth factor receptor pathway substrate 8 (EPS8), called CP-EPS8-NLS, can cross the cellular membrane and interfere with the nuclear translocation of EPS8, leading to inhibited cell viability and proliferation in acute myeloid leukemia (AML) (112). It has also been revealed that cell-penetrating peptide TAT-conjugated gambogic acid promotes tumor apoptosis via reactive oxygen species (ROS)-mediated apoptosis by increasing the ROS level in bladder cancer cells (113).

Development of cell-permeable therapeutic peptides with polar side chains has used advantage of adding methyl groups, asparagine residues and D-amino acids (45). Similarly, another drug delivery system, known as nanoparticles, can carry ACPs to tumor sites without enzymatic degradation and can then enter inaccessible tumor sites (114). However, anticancer drug-carrying nanoparticles should be optimized for synergistic effect, drug release control, circulating stability and drug combination (115). Moreover, binding peptides could be modified to protect enzymatic digestion, penetrate cancer cell or organelle membranes, specifically bind to cancer targets and stimulate biological cells around tumor environments (116).

\section{Cell stimulating peptides}

Immune system stimulating peptides. Host defense mechanisms against pathogens or transformed cells, such as the cancer cells, is a novel therapeutic approach that involves recruiting the immune cells into the tumors (117). Antigenic peptide-human leukocyte antigen class I complex respond to cytotoxic $\mathrm{CD} 8^{+} \mathrm{T}$-cells against malignant diseases and brain tumors (118). However, ACP-produced vaccines exhibit poor immunogenicity, and thus require adjuvants to increase specific immune responses (119). For example, E75 peptide breast cancer vaccine (Her2 p369-p377) containing polyactin A can increase $\mathrm{CD}^{+}$and $\mathrm{CD}^{+} \mathrm{T}$ lymphocytes, enhance proliferation of splenocytes and increase levels of interferon- $\gamma$ in splenocytes (120). Furthermore, a melittin-RADA 32 hybrid peptide hydrogel-linked doxorubicin can recruit activated natural killer cells in the primary melanoma tumor, resulting in growth retardation, as well as activation of dendritic cells of draining lymph nodes and production of cytotoxic T-cells against the remaining tumors (121). Tyrosinase-related protein 2 melanoma antigen peptide nanovaccine combined with $\mathrm{CpG}$ adjuvant could slowly result in growth of the melanoma tumor (122). Moreover, the 5-mer peptide, A-P-D-T-R, is a potential target for immunotherapy against breast cancer due to its highly immunogenic property that exists within the variable number of tandem repeats found in all mucins, particularly mucin1, which is increased by 10 -fold in adenocarcinomas (123). Some peptide vaccines have been studied in phase I/II clinical trials (124-126). For instance, an adjuvant multi-peptide vaccine (UroRCC) was administered in patients with metastatic renal cell carcinoma following metastasectomy (127). Furthermore, a multipeptide vaccine (IMA950) containing 11 tumor-associated peptides, which targets IMA950 antigens, has been used as a tumor-targeting vaccine involving the T-cell response in grade II and III glioma (128). In metastatic hormone-naïve prostate cancer, the novel human telomerase reverse transcriptase (hTERT) peptide vaccine UV1 can induce an immune response, affecting the prostate-specific antigen level (129). A vaccine containing peptides can also be an adjuvant for activating the immune system. For instance, Hp91 peptide has formed the adjuvant for a protein vaccine against human papillomavirus to control cervical cancer (130). Therefore, immune system stimulating peptides are an alternative cancer therapy to control metastasis and eradicate cancer cells by activating host immunity with the specific tumor antigens.

Hormone stimulating peptides. The therapeutic peptides can inhibit cancer cell proliferation by controlling hormone release via their receptors (131). Cancer cells can produce hormones, such as growth hormone-releasing hormone (GHRH), to stimulate the pituitary gland and then the release of growth hormone $(132,133)$. In a previous study, a GHRH antagonist was synthesized to inhibit proliferation in AML cell lines, including K562, THP-1 and KG-1a cells (134). Follicle stimulating hormone (FSH), for which the circulating level is increased by leptin, serves an important role in the initiation and the proliferation of the ovarian cancer cells (135). Moreover, the obese OB3 peptide, a derivative of leptin, may prevent leptin-induced ovarian cancer cells by disrupting leptin-induced ovarian cancer cell proliferation signal via stimulation of STAT3 phosphorylation and estrogen receptor $\alpha$-activation (135). Furthermore, nanoparticle drug vehicles containing 21-amino acid peptides [YTRDLVYGDPARPGIQGTGTF (D-FP21)] conjugated to polyethylenimine and methoxy polyethylene glycol target the FSH receptor, leading to anti-proliferative effects on ovarian cancer (136). For chemotherapeutic improvement of metastatic hormone-refractory prostate cancer, it was found that the AlkB homolog 2 proliferating cell nuclear antigen (PCNA) interacting motif peptide targeting PCNA, an essential scaffold protein, in combination with docetaxel could decrease prostate volume and inhibit cancer cell regrowth in vivo (137).

\section{Development of therapeutic ACPs}

The issues with conventional therapeutic agents associated with the majority of cancer drugs, include poor water solubility, lack of target specificity and capability, non-specific distribution, system cytotoxicity and low therapeutic index, can be solved by creating a water-soluble form, targeting the delivery of ACPs, non-systemic side effects and specific treatment efficacy (138). Numerous natural peptides derived from natural products, such as bioactive peptides, are applied in cancer therapy (139). 
Although naturally bioactive peptides exhibited beneficial biocompatibility and low cytotoxicity, a number of bioactive peptides cannot provide the active targeting, cell uptake, cancer cell cytotoxicity and targeted delivery (140). The natural active peptides can be modified to novel peptides with special properties, including specificity, higher cell penetration, cancer cell cytotoxicity and therapeutic efficacy with no side effect. The present review focused on the therapeutic peptide development from natural peptides to modified peptides and targeting peptides for increasing the specific cancer cell targets.

Natural peptides. Anticancer peptides have been discovered and modified from antimicrobial peptides, and these resources produce natural peptides from various organisms, such as marine, plant, yeast, fungi, bacteria and bovine $(141,142)$. Antimicrobial and anticancer peptides, especially cationic peptides, can kill both bacteria and cancer cells due to the similar negative net charge on their membranes (143). Proteins from nutrients can release bioactive peptides via enzymatic hydrolysis, gastrointestinal digestion or during fermentation (144). Bioactive peptides discovered from natural peptides have an electrostatic interaction between the peptides and cell membrane, leading to cancer cell or mitochondrial membrane disruption and then necrosis or apoptosis (145). For example, bioactive milk-derived peptides released during digestion have a vital role in cancer prevention (146). Moreover, germinated soybean protein-derived peptides from enzymatic hydrolysis exert antiproliferative activity against human colorectal cancer cells (147). It has also been shown that the extracted peptides from Lentinus squarrosulus mushrooms can mediate human lung cancer cells via apoptosis (148). Cyclic peptides isolated from marine cyanobacteria, such as Urumamide, exhibited low proliferative inhibitory activity on human cancer cells (149). Additional examples of natural peptides that have anticancer properties are presented in Table II and Fig. 3A. The majority of natural peptides that exert effects against cancer cell survival are $\alpha$-helical folding peptides that have cationic properties $(150,151)$. However, a minority of peptides, including other folding with neutral or anionic peptides, are able to disrupt cancer cell survival (152). Recently, a number of anionic antimicrobial peptides that originate from amphibians, including frogs, toads, newts and salamanders across Africa, South America and China, demonstrated anticancer activity (153). Thus, natural ACPs can exhibit both cationic and anionic or neutral properties; also, the majority of cationic peptides are found to have a significant cytotoxic effect against cancer cells compared with anionic or neutral peptides. In the future, these natural ACPs can be modified to further ACP development.

Modified peptides. Highly cationic and amphipathic peptide properties can be synthesized and designed via in silico creations. For example, some chemical groups, such as acetylation or amidation, are added into the natural peptides to increase the cationic properties and target cell specificity (162). Replacement of D-amino acids in an amphipathic peptide, KLALKLALKALKAAKLA-NH ${ }_{2}$, and a hydrophobic interaction can increase the membrane-disrupting effect on high negative surface charge bilayers, which then promotes peptide penetration into the inner membrane regions (163). Moreover, the folding and formation of peptides, such as the $\alpha$-helix or cyclization, results in an increase in anticancer properties and stability $(164,165)$. It has also been revealed that fewer helical peptides can decrease the bilayer disruption activity (163), and that cyclic peptides can act on cell permeability (45). Furthermore, substitution, deletion or addition of positively charged or polar and non-polar amino acids on natural peptides could modify their properties to improve therapeutic application $(164,165)$. Some modified peptides are displayed in Table III and Fig. 3B.

Besides the aforementioned modifications, ACPs have been constructed via genetic engineering, including anticancer fusion peptides; for example, the structure of bovine lactoferricin and hexapeptide derived from bovine milk protein for ovarian cancer treatment (166). NT4 peptides bound to GAG chains of heparan sulfate proteoglycans have a modulatory effect on the cancer cell migration and invasion ability (167). A recombinant protein consisting of iRGD (CRGDKGPDC)-conjugated KLA peptide (KLAKLAKKLAKLAK) exerts a pro-apoptotic activity and high penetration to tumor tissue and cells for gastric cancer treatment (40). Collectively, modified peptides can be developed to improve anticancer properties and the effect on the cancer targets directly.

Targeting peptides. The discovery of cancer cell targets can promote cell target specificity to avoid healthy cell damage (172). Targeting peptides on various cancer cell types should bind to cancer cell targets and eliminate cancer cells at the same time (173). Molecular targets in cancer cells are important for clinical therapy, including vascular endothelial growth factor, RAS/mitogen-activated protein kinase pathway inhibitors, aurora kinase inhibitors or endothelin receptor antagonists $(174,175)$. Some molecular targets can induce an immune response, such as cytokines, while others directly bind to specific cancer cell biomarkers $(175,176)$. Upregulation of specific cancer proteins or peptides has been used as cancer targets (139). For instance, high expression levels of MDM2 proto-oncogene (MDM2) and MDM4 regulator of p53 (MDMX), as negative regulators of tumor suppressor protein $\mathrm{p53}$, and upregulated expression of the cell surface receptor CD33 have been targeted for AML therapy (177). Lanthanide oxyfluoride nanoparticle (LONp) bound dual-specific peptide antagonists of MDM2 and MDMX (PMI) and antiCD33-LONp-PMI can activate the p53 pathway, thus inducing AML cell apoptosis (177). Furthermore, upregulated urokinase plasminogen activator receptors (UPAR) on cancer cells are targeted to uptake a specific peptide, 68Ga-labeled AE105 peptide, as uPAR PET-probes, into U87MG tumor cells (178). Examples of the targeting peptides are presented in Table IV and Fig. 3C. Besides disturbing cancer cell survival, targeting peptides for cancer cell labeling was an advantage for cancer cell detection and diagnosis. For example, 99mTc-(tricine)-HYNIC-Lys-FROP peptides were taken up by breast cancer cells for tumor targeting and molecular imaging (179). Therefore, targeting peptides can specifically and directly bind and destroy cancer cells, but not healthy cells. However, their targets are difficult to discover and develop for specific cancer cell therapy.

\section{Anticancer peptides in clinical trials}

Several synthetic peptide-based drugs and vaccines are currently undergoing clinical trials. The National Library 


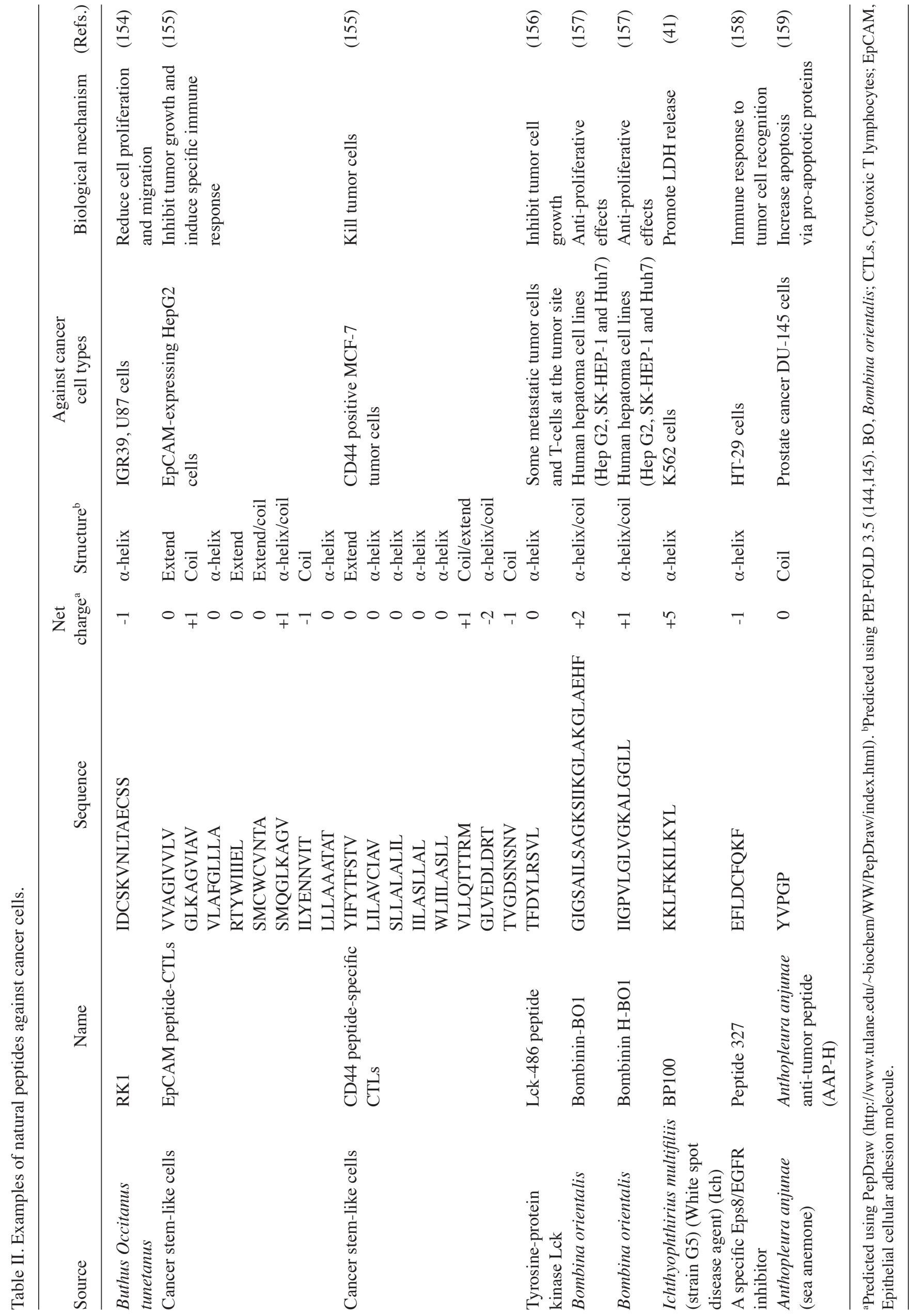




$$
\begin{aligned}
& \text { 25 } 503\{3
\end{aligned}
$$

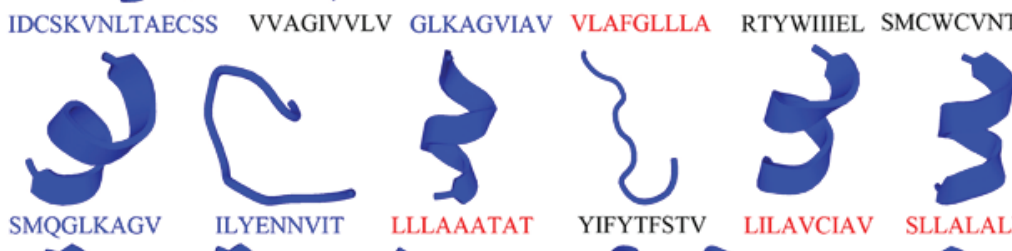

$$
\begin{aligned}
& 3825
\end{aligned}
$$

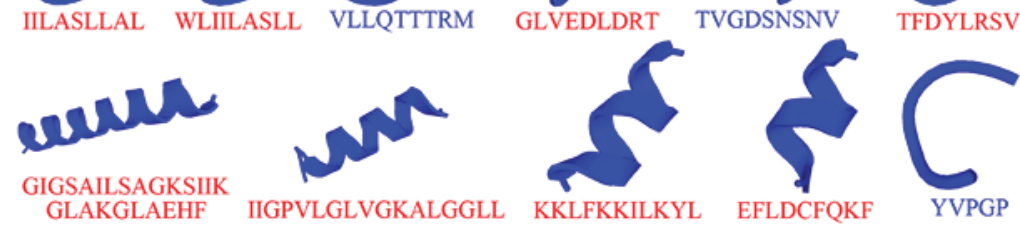

$$
\begin{aligned}
& \text { Com } \approx \frac{\xi}{2} \\
& \text { हु) } \\
& \frac{2}{2} \frac{5}{2} \\
& \text { अ के }
\end{aligned}
$$


of Medicine (NLM) at the National Institutes of Health (NIH) provides and updates clinical trial information on the ClinicalTrials.gov website. A total of 792 studies between 1995-2019 were identified and searched for 'cancer', 'peptide', 'drug' or 'biological' key words, excluding non-anti-cancer peptide interventions such as behavior and surgery. The search result is presented in Fig. 4.

For example, CIGB-300, an amidated disulfide cyclic undecapeptide fused to the TAT cell-penetrating peptide via a $\beta$-alanine spacer, inhibits CK-2-mediated phosphorylation leading to cancer cell apoptosis in patients with cervical and non-small cell lung cancer (185-187). Wilms' tumor 1 (WT1) peptide-based vaccination combined with the adjuvant drug OK-432 administered to pediatric patients with a solid tumor has been demonstrated to be safe for these children (188). Furthermore, WT1-pulsed dendritic cell vaccine has been used to treat patients with surgically resected pancreatic cancer under a phase I study (189). A modified 9-mer WT1 peptide vaccine was also used in patients with gynecological cancer for inducing myeloid dendritic cells, and was demonstrated to be associated with cytotoxic T-cell activation (190). Subsequently, WT1 peptide vaccine therapy was evaluated in patients with gynecological cancer in a phase II clinical trial (191). A target of esophageal squamous cell carcinoma and lung cancer types is lymphocyte antigen 6 complex locus K (LY6K), which is expressed in gastric cancer (192). LY6K-177 peptide vaccine emulsified with Montanide ISA 51 was evaluated in patients with gastric cancer as a phase I clinical trial, and was found to be tolerated by patients with advanced gastric cancer (50\% of patients with gastric cancer had stable disease and $16 \%$ patients had a tumor contraction effect) (192).

B-cell lymphocytic leukemia and pancreatic cancer have demonstrated a high level of telomerase activity (193). GV1001, a peptide based-cancer vaccine derived from the hTERT (hTERT 616-626; EARPALLTSRLRFIPK), was administrated in patients with non-resectable pancreatic cancer undergoing a dose-escalating phase I/II study (194); GV1001 was capable of inducing $\mathrm{CD}^{+}$and $\mathrm{CD} 8^{+} \mathrm{T}$-cells, interacting with professional antigen-presenting cells and then engulfing dead tumor tissue or cells (194). Moreover, GV1001 may be a candidate vaccine in patients with B-cell chronic lymphocytic leukemia that exhibit telomerase-specific leukemic cells (195).

A combination of the ACPs and other drugs have also been evaluated in phase I trials, such as cyclodepsipeptide plitidepsin and bevacizumab in refractory solid tumors (196). For the binding peptide strategy, a carrier peptide, as a luteinizing hormone-releasing hormone (LHRH) agonist, is linked to the cytotoxic analogs of LHRH for cancer expressing receptors for LHRH (197). The LHRH agonist under phase II clinical trial exhibits anticancer activity in LHRH receptor-positive cancer types, such as human endometrial, ovarian and prostate cancer (197). Previously, a personalized peptide vaccination (PPV) has been developed as a novel approach for a cancer vaccine to boost the immune response using specific peptides for each patient (198). The peptides for PPV treatment under a randomized phase II trial in patients with bladder cancer were selected from the candidate peptides, according to human leukocyte antigen types and peptide-reactive IgG titers, to observe progression-free survival, overall survival, immune 
Table IV. Examples of targeting peptides bind to specific cancer cells.

\begin{tabular}{|c|c|c|c|c|c|}
\hline Name & Sequence & $\begin{array}{l}\text { Net } \\
\text { charge }^{\mathrm{a}}\end{array}$ & Structure $^{b}$ & Targeting cancer cell types & (Refs.) \\
\hline CSP-GD & GDALFSVPLEVY & -2 & Extend/coil & Human cervical cancer & (139) \\
\hline CSP-TL & TLHQPPSSANWI & 0 & Coil & derived cells $(\mathrm{SiH})$ & \\
\hline CSP-FT & FTPGGNTYAGQP & 0 & Coil & & \\
\hline CSP-SI & SIDDQRDVAEFA & -3 & Coil/ $/ \alpha$-helix & Human cervical cancer & (139) \\
\hline CSP-KQ & KQNLAEG & 0 & Coil $/ \alpha$-helix & derived cells $(\mathrm{C}-33 \mathrm{~A})$ & \\
\hline p160 & VPWMEPAYQRFL & 0 & Coil/ $\alpha$-helix & $\begin{array}{l}\text { Neuroblastoma and breast } \\
\text { cancer cell lines }\end{array}$ & $(180,181)$ \\
\hline Polyarginine (R11) & RRRRRRRRRRR & +11 & $\alpha$-helix & Bladder cancer & (182) \\
\hline DN-C16orf74 & $\begin{array}{l}\text { RRRRRRRRRRR-GGG-KHLD } \\
\text { VPVIVIPPTPT }\end{array}$ & +11 & $\alpha$-helix-coli-extend & Pancreatic cancer cells & (183) \\
\hline$\alpha$-helix HSP70 peptide & $\begin{array}{l}\text { ACFAEKFKEAVKDYFAKFWD- } \\
\text { GSG-TKDNNLLGRFELSG }\end{array}$ & 0 & $\alpha$-helix-coli-extend & $\begin{array}{l}\text { Tumor regression on mice } \\
\text { B16OVA melanoma models }\end{array}$ & $(184)$ \\
\hline
\end{tabular}

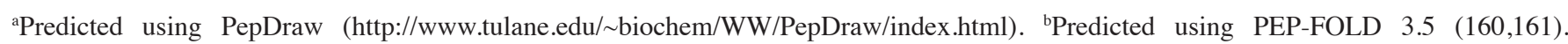
CSP, cancer-specific targeting peptide; HSP, heat shock protein.

response and toxicity (198). Similarly, 19 mixed peptides were selected from 31 PPVs according to the anti-tumor immunological effect, and the safety profiles for patients with metastatic breast cancer were also assessed in a phase II clinical trial (199). While some peptides, such as gp100:209-217 $(210 \mathrm{M}) /$ Montanide $^{\mathrm{TM}}$ ISA-51/Imiquimod for high risk melanoma and E39 peptide/GM-CSF vaccine plus E39 booster for ovarian cancer, have been approved by the Food and Drug Administration (FDA), these have been improved in clinical therapy, such as peptide boronate bortezomib (200-202). The peptide boronate bortezomib is a reversible $26 \mathrm{~S}$ proteasome inhibitor, degenerating several intracellular proteins, with antitumor and antiproliferative activities and can be used in multiple myeloma therapy (202). Due to adverse effects, such as hematotoxicity and peripheral neuropathy, poor penetration into solid tumors and low clinical stability and bioavailability, bortezomib was developed for delivery using nanoparticles, and treatment for bortezomib resistant multiple myeloma was improved using target chemical modification during synthetic processes $(203,204)$. Additional ACP examples are presented in Table V. As aforementioned, various cancer vaccines have been produced using ACPs and ACPs combined with adjuvants or drugs, and the effects of carrier peptides on targeting cancer cell directly and/or by activating immune response have been tested in clinical trials for safety, side effects and effectiveness.

\section{Future direction}

Although ACPs have a number of disadvantages, such as biological instability, low bioavailability, short half-life, protease sensitivity, poor pharmacokinetics and first-pass metabolism, their most notable advantage is the protein-protein interaction with a target, thus overcoming limitations via designing peptide modifications and conjugation to improve affinity, stability and selectivity $(205,206)$. For example, the peptide $\mathrm{BBN}_{7-14}\left(\mathrm{Gln}\right.$-Trp-Ala-Val-Gly-His-Leu-Met- $\left.\mathrm{NH}_{2}\right)$ composed of natural amino acids has a higher binding affinity with the CFPAC-1 cell line compared with the modified peptide GB-6 (Gln-5-Htp- $\beta$-Ala-Nva-Gln-His- $\mathrm{NH}_{2}$ ) that consists of unnatural amino acids (in vitro). However, in vivo, $\mathrm{BBN}_{7-14}$ has a reduced tumor-targeting ability compared with GB-6, which is stable against protease-mediate degradation and has a slightly lower uptake and slow metabolism (207). Currently, ACPs have been modified to improve specific cancer cell targets and enhance cancer cell elimination. Some anticancer peptides as drugs and vaccinations have been tested in phase I/II clinical trials (175). For example, dTCApFs, a natural hormone peptide for the treatment of advanced or metastatic solid tumors, enters the cells via the Toll/interleukin-1 receptor superfamily, suppresses angiogenic factors and induces anticancer cytokine production and ER stress, leading to cancer cell apoptosis (208). dTCApFs anticancer activity in humans was firstly studied in a phase I clinical trial by investigating the safety and efficacy with regards to both pharmacokinetics and pharmacodynamics, with intravenous dTCApFs $\left(6-96 \mathrm{mg} / \mathrm{m}^{2} ; 3\right.$ times/week; in consecutive 28-day cycles) (209). The intravenous dTCApFs is decreased at lower limit of detection in serum after 24-h administration and its concentration in serum is present in dose-dependent manner (209). Furthermore, ACPs have been combined with immunogens for clinical therapeutic improvement (210). Upregulation of molecular cancer targets, such as Ras protein that has been discovered in various cancer cell types (lung, colon and pancreatic), could also be direct targets for ACP development (211). The aim of ACP therapy should promote cancer cell death and intermit tumor regression, without contributing to tumorigenesis and resistance in cancer cell treatment (212). The first ACP approved by the FDA was the peptide boronate bortezomib (Velcade ${ }^{\circledR}$ ) for multiple myeloma treatment in 2003 and mantle cell lymphoma in 2006 (213). In the near future, combination therapy with a drug or vaccine containing i) the specific targeting peptides, ii) the ACPs and 
A

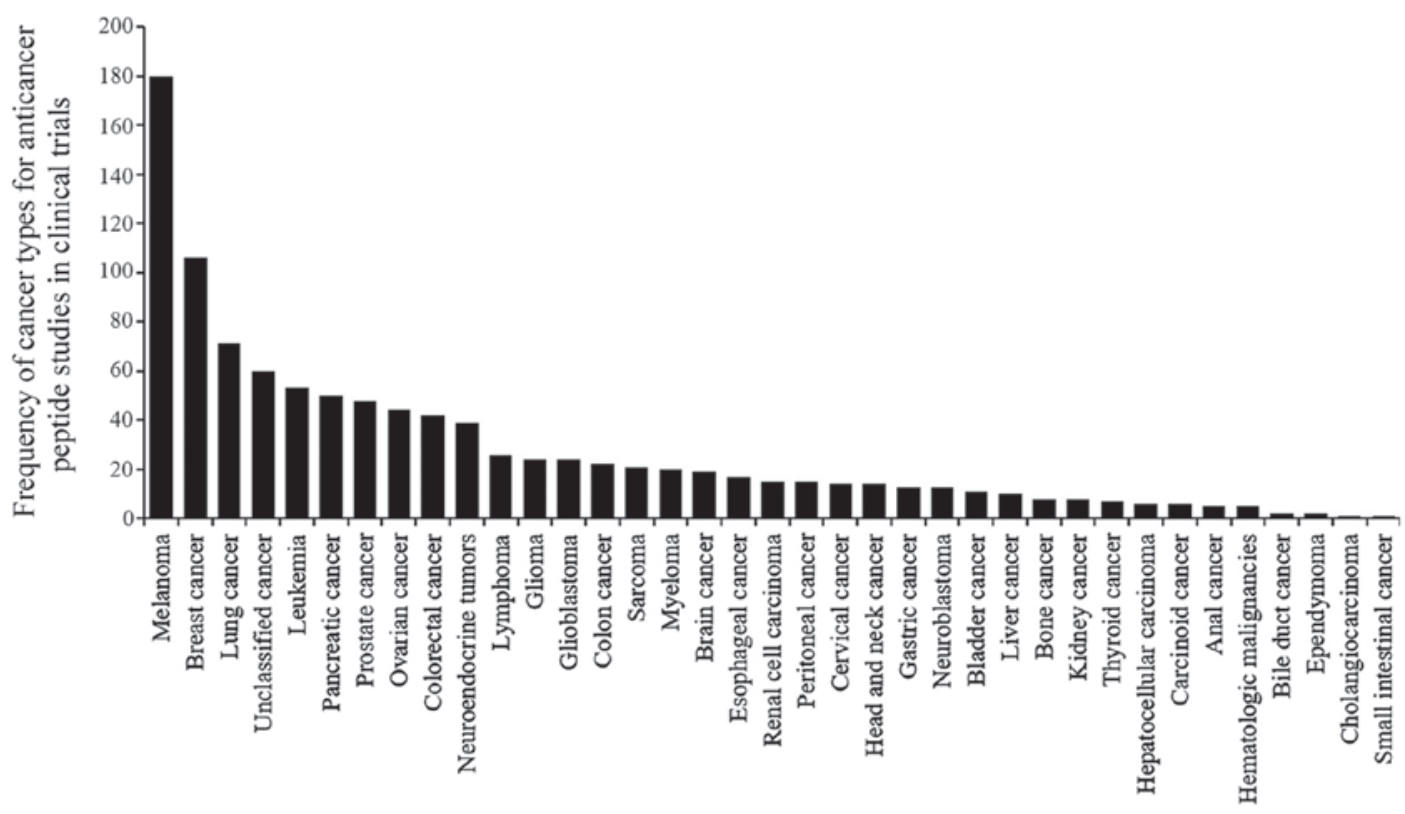

B

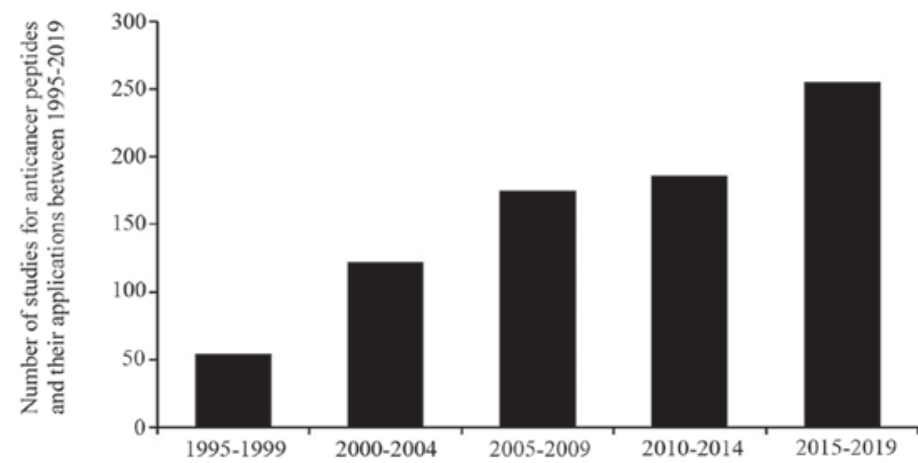

$\mathrm{C}$

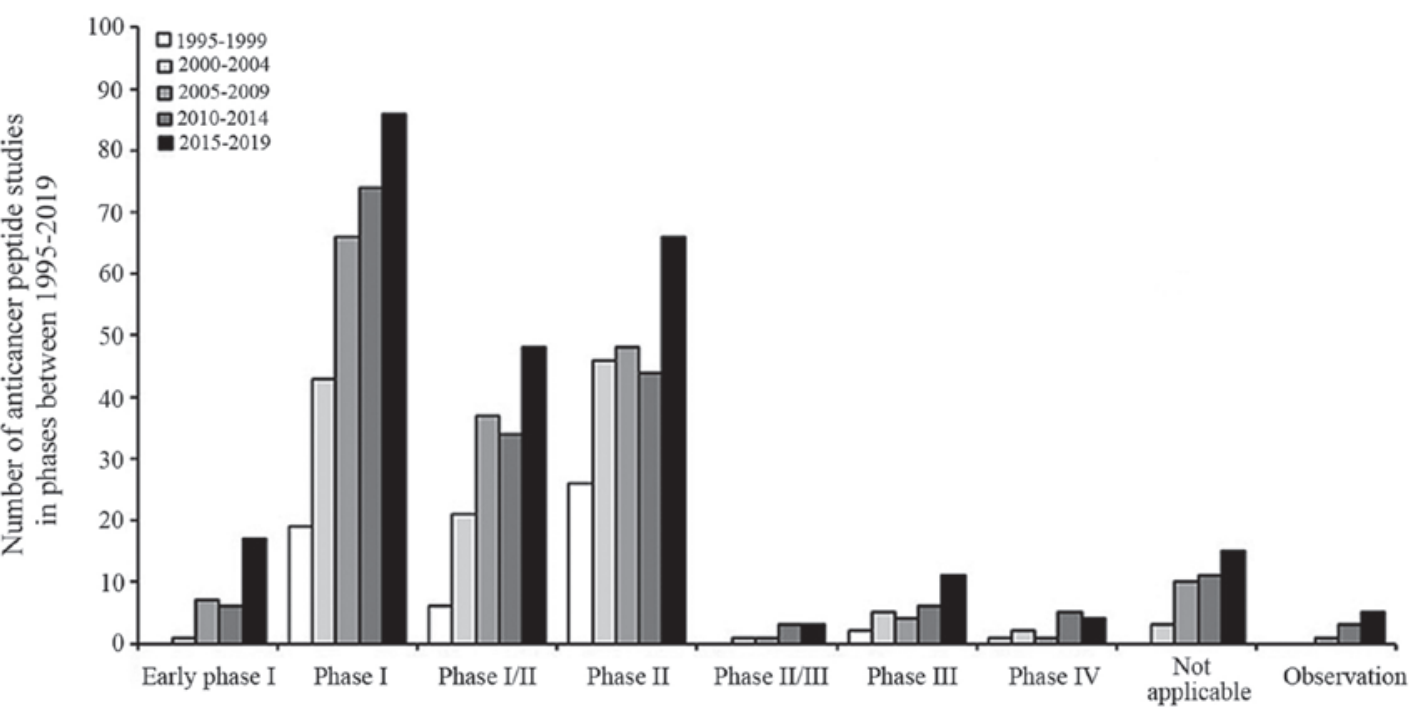

Figure 4. Number of ACP studies for the drug and biological intervention. (A) Frequency of cancer types from 792 ACP studies, which were submitted on the ClinicalTrials.gov website, including 36 cancer types and unclassified cancer types. The unclassified cancer types were reported as solid tumors, cancer or neoplasms. (B) Number of ACP studies in every 5-year period between 1995-2019 was continuously increased. (C) Furthermore, from 1995-2019, $>98 \%$ of these ACP studies were an intervention study type, including clinical trial in early phase I, phase I, I/II, II, II/III, III, IV and not applicable, while <2\% of them were an observation study type, which cannot assign a specific intervention or treatment. Source:www.clinicaltrials.gov search on Feb 4, 2020 with drug, biological and peptide key words in cancer. ACP, anticancer peptide.

iii) the cell-penetrating peptides and/or the conjugated delivery materials (such as liposome, nanoparticles or adjuvants) may facilitate the development of cancer therapy with cancer cell specificity, stability, safety and efficacy, without healthy cell eradication (214). ACP construction for specific cancer cell targets, and predictive, preventive and personalized medicine may be beneficial to the cancer research field due to the different complexity of the whole-body system in each individual (215). 
Table V. Examples of ACPs in clinical trials (source: www.ClinicalTrials.gov).

\begin{tabular}{lll}
\hline Phases & Biological peptides & Conditions
\end{tabular}

Early phase 1 MUC-1 peptide vaccine, poly ICLC, Breast cancer

MUC1 peptide-poly-ICLC adjuvant vaccine

HER-2/neu peptide vaccine

GAA/TT-peptide vaccine and poly-ICLC

Peptide vaccine + poly-ICLC

Gag:267-274 peptide vaccine

Phase 1

HPV16 E7 peptide-pulsed

autologous DCs

NY-ESO-1b peptide plus CpG

7909 and Montanide ISA-5

Antiangiogenic peptide vaccine

RNF43-721

LY6K, VEGFR1, VEGFR2

HLA-A*0201 or HLA-A*0206restricted URLC10 peptides

Phase 1/Phase 2 MAGE-3.A1 peptide and CpG 7909 Malignant melanoma VEGFR1-1084, VEGFR2-169 HER-2/neu peptide vaccine HLA-A*2402 or A*0201 restricted Solid tumors peptides

\section{Modified CEA peptide}

Phase 2

Phase $3 \quad$ PR1 leukemia peptide vaccine

synthetic human papillomavirus

16 E6 peptide

gp100:209-217(210M), HPV 16

E7:12-20

WT1 126-134 peptide

G250 peptide

Melanoma helper peptide vaccine, multi-epitope melanoma peptide vaccine

Phase 4
Degarelix (LHRH antagonist)
Breast cancer Pancreatic cancer Breast cancer

Pancreatic adenocarcinoma
Cervical cancer

Melanoma

Acute myeloid leukemia

Metastatic renal cell carcinoma

Melanoma

Leukemia

Prostatic neoplasms
A positive anti-MUC1 antibody response

Peptide-specific interferon- $\gamma$ producing T-cell and peptide-specific IL-5 producing T-cell responses Astrocytoma, oligoastrocytoma, Induction of GAA-specific T-cell response

Astrocytoma, oligoastrocytoma, Infiltration of GAA-specific T-cells inodendroglioma

Cervical cancer

Vaccine peptide-specific CTL response Pulsed autologous DCs immunotherapy

NY-ESO-1 specific humoral and cellular immunity

Peptide specific CTL response

Specific CTL induction in vitro

Immune responses including LY6K,

VEGFR1 and VEGFR2 specific T-cells Immunological responses including peptides specific CTL, antigen cascade, regulatory T-cells, cancer antigens and HLA levels.

Detectable CTL response

Peptide specific CTL response

HER2-specific T-cell response

Various immunological responses

including peptides specific CTL, antigen cascade, regulatory T-cells, cancer antigens and HLA levels

T-cell response with modified CEA peptide

Immunological response to HPV

T-cell immunity to gp100 peptide and to E7 12-20 papilloma virus peptide

Generation of T-cell response

G250-specific CTL response

CTL response, helper T-cells response to $6 \mathrm{MHP}$

Immune response to PR1-HLA-A2 tetramer

Binds to GnRH receptors and blocks interaction with $\mathrm{GnRH}$

From ClinicalTrials gov searched on January 31, 2020. CTL, cytotoxic T-cell lymphocytes; GnRH, gonadotropin-releasing hormone; CEA, carcinoembryonic antigen; HPV, human papillomavirus; HER, human epidermal growth factor receptor; VEGFR, vascular endothelial growth factor receptor; MAGE-3, melanoma-associated antigen 3; RNF, ring finger protein; NY-ESO, New York esophageal squamous cell carcinoma; MUC, mucin.

Besides the aforementioned therapeutic peptides, peptides with specific cancer cell targets are applied to bind the cancer cell targets for cancer detection and therapy $(216,217)$. For example, a sodium pump $\mathrm{Na}^{+} / \mathrm{K}^{+}$ATPase $\alpha 1$-targeted peptide 
for positron emission tomography imaging of breast cancer, as peptide-based platform on dual-targeted molecular imaging, is able to more obviously visualize the disease state of a patient, leading to improved informed treatment decisions $(218,219)$.

\section{Conclusions}

ACP therapy affects molecular targets, binds the anticancer drugs and stimulates biological systems involving cancer and healthy cell environments. Notably, natural and synthetic peptides have been developed as novel strategies against cancer types. Natural anticancer peptides can be modified to enable high penetration, specific cancer cell targets, increase efficacy and reduce side effects. A number of ACPs have been demonstrated to be anti-proliferative, apoptotic and proliferation inhibitors in various cancer cell types, both in vitro and in vivo, leading to clinical trials for the evaluation of cancer treatment. The development of drug or vaccine technology could further ACPs in design, synthesis and delivery to eliminate cancer cells directly or by affecting the anticancer immune responses (220). Collectively, it was suggested ACPs may promote cancer drugs or vaccine development to decrease emerging cases and mortality rates in the future.

\section{Acknowledgements}

The authors would like to thank Dr Thitinee Vanichapol, Division of Hematology and Oncology, Department of Pediatrics, Faculty of Medicine, Ramathibodi Hospital, Mahidol University for revising the manuscript and providing kind suggestions.

\section{Funding}

This study was financially supported by BRAND'S Health Research Award 2017 (Cerebos Award 2017), Children Cancer Fund under the Patronage of HRH Princess Soamsawali and Faculty Staff Development Program of Faculty of Medicine Ramathibodi Hospital, Mahidol University, Thailand (grant no. BHR2017).

\section{Availability of data and materials}

The datasets used and/or analyzed during the present study are available from the corresponding author on reasonable request.

\section{Authors' contributions}

WC wrote and edited the manuscript and was involved in the creation of the figures and data analysis. All authors were involved in the drafting and revising of the manuscript. All authors read the manuscript and approved the final version.

\section{Ethics approval and consent to participate}

Not applicable.

\section{Patient consent for publication}

Not applicable.

\section{Competing interests}

The authors declare that they have no competing interests.

\section{References}

1. Wang SH and Yu J: Structure-based design for binding peptides in anti-cancer therapy. Biomaterials 156: 1-15, 2018.

2. Wang X, Zhang L, Ding N, Yang X, Zhang J, He J, Li Z and Sun LQ: Identification and characterization of DNAzymes targeting DNA methyltransferase I for suppressing bladder cancer proliferation. Biochem Biophys Res Commun 461: 329-333, 2015.

3. Ingram JR, Blomberg OS, Rashidian M, Ali L, Garforth S, Fedorov E, Fedorov AA, Bonanno JB, Le Gall C, Crowley S, et al: Anti-CTLA-4 therapy requires an Fc domain for efficacy. Proc Natl Acad Sci USA 115: 3912-3917, 2018.

4. Di JX and Zhang HY: C188-9, a small-molecule STAT3 inhibitor, exerts an antitumor effect on head and neck squamous cell carcinoma. Anticancer Drugs 30: 846-853, 2019.

5. Brun S, Bassissi F, Serdjebi C, Novello M, Tracz J, Autelitano F, Guillemot M, Fabre P, Courcambeck J, Ansaldi C, et al: GNS561, a new lysosomotropic small molecule, for the treatment of intrahepatic cholangiocarcinoma. Invest New Drugs 37: 1135-1145, 2019.

6. Jahangirian H, Kalantari K, Izadiyan Z, Rafiee-Moghaddam R, Shameli $\mathrm{K}$ and Webster TJ: A review of small molecules and drug delivery applications using gold and iron nanoparticles. Int J Nanomedicine 14: 1633-1657, 2019.

7. Tyagi A, Tuknait A, Anand P, Gupta S, Sharma M, Mathur D, Joshi A, Singh S, Gautam A and Raghava GP: CancerPPD: A database of anticancer peptides and proteins. Nucleic Acids Res 43 (Database Issue): D837-D843, 2015.

8. Thundimadathil J: Cancer treatment using peptides: Current therapies and future prospects. J Amino Acids 2012: 967347, 2012.

9. Vlieghe P, Lisowski V, Martinez J and Khrestchatisky M: Synthetic therapeutic peptides: Science and market. Drug Discov Today 15: 40-56, 2010.

10. Otvos L Jr: Peptide-based drug design: Here and now. Methods Mol Biol 494: 1-8, 2008.

11. Hoskin DW and Ramamoorthy A: Studies on anticancer activities of antimicrobial peptides. Biochim Biophys Acta 1778: 357-375, 2008.

12. Rodrigues EG, Dobroff AS, Taborda CP and Travassos LR: Antifungal and antitumor models of bioactive protective peptides. An Acad Bras Cienc 81: 503-520, 2009.

13. Droin N, Hendra JB, Ducoroy P and Solary E: Human defensins as cancer biomarkers and antitumour molecules. J Proteomics 72: 918-927, 2009

14. Simons K and Ikonen E: How cells handle cholesterol. Science 290: 1721-1726, 2000.

15. Sok M, Sentjurc M and Schara M: Membrane fluidity characteristics of human lung cancer. Cancer Lett 139: 215-220, 1999.

16. Zwaal RF and Schroit AJ: Pathophysiologic implications of membrane phospholipid asymmetry in blood cells. Blood 89: 1121-1132, 1997.

17. Schweizer F: Cationic amphiphilic peptides with cancer-selective toxicity. Eur J Pharmacol 625: 190-194, 2009.

18. Utsugi T, Schroit AJ, Connor J, Bucana CD and Fidler IJ: Elevated expression of phosphatidylserine in the outer membrane leaflet of human tumor cells and recognition by activated human blood monocytes. Cancer Res 51: 3062-3066, 1991.

19. Harris F, Dennison SR, Singh J and Phoenix DA: On the selectivity and efficacy of defense peptides with respect to cancer cells. Med Res Rev 33: 190-234, 2013.

20. Li G, Huang Y, Feng Q and Chen Y: Tryptophan as a probe to study the anticancer mechanism of action and specificity of alpha-helical anticancer peptides. Molecules 19: 12224-12241, 2014.

21. Marqus S, Pirogova E and Piva TJ: Evaluation of the use of therapeutic peptides for cancer treatment. J Biomed Sci 24: 21, 2017.

22. Roudi R, Syn NL and Roudbary M: Antimicrobial peptides as biologic and immunotherapeutic agents against Cancer: A comprehensive overview. Front Immunol 8: 1320, 2017.

23. Alves AC, Ribeiro D, Nunes $C$ and Reis S: Biophysics in cancer: The relevance of drug-membrane interaction studies. Biochim Biophys Acta 1858: 2231-2244, 2016. 
24. Yamaji-Hasegawa A and Tsujimoto M: Asymmetric distribution of phospholipids in biomembranes. Biol Pharm Bull 29: 1547-1553, 2006.

25. Clark MR: Flippin' lipids. Nat Immunol 12: 373-375, 2011.

26. Deliconstantinos G: Physiological aspects of membrane lipid fluidity in malignancy. Anticancer Res 7: 1011-1021, 1987.

27. Ran S, Downes A and Thorpe PE: Increased exposure of anionic phospholipids on the surface of tumor blood vessels. Cancer Res 62: 6132-6140, 2002.

28. Stafford JH and Thorpe PE: Increased exposure of phosphatidylethanolamine on the surface of tumor vascular endothelium. Neoplasia 13: 299-308, 2011.

29. Barcelo-Coblijn G, Martin ML, de Almeida RF, NogueraSalva MA, Marcilla-Etxenike A, Guardiola-Serrano F, Lüth A, Kleuser B, Halver JE and Escribá PV: Sphingomyelin and sphingomyelin synthase (SMS) in the malignant transformation of glioma cells and in 2-hydroxyoleic acid therapy. Proc Natl Acad Sci USA 108: 19569-19574, 2011.

30. Preetha A, Huilgol N and Banerjee R: Comparison of paclitaxel penetration in normal and cancerous cervical model monolayer membranes. Colloids Surf B Biointerfaces 53: 179-186, 2006.

31. Zhao L, Feng SS and Go ML: Investigation of molecular interactions between paclitaxel and DPPC by Langmuir film balance and differential scanning calorimetry. J Pharm Sci 93: 86-98, 2004.

32. Logozzi M, Spugnini E, Mizzoni D, Di Raimo R and Fais S: Extracellular acidity and increased exosome release as key phenotypes of malignant tumors. Cancer Metastasis Rev 38: 93-101, 2019

33. Cardone RA, Casavola V and Reshkin SJ: The role of disturbed $\mathrm{pH}$ dynamics and the $\mathrm{Na}+\mathrm{H}+$ exchanger in metastasis. Nat Rev Cancer 5: 786-795, 2005.

34. Jobin ML and Alves ID: On the importance of electrostatic interactions between cell penetrating peptides and membranes: A pathway toward tumor cell selectivity? Biochimie 107: 154-159, 2014.

35. Peyressatre M, Prevel C, Pellerano M and Morris MC: Targeting cyclin-dependent kinases in human cancers: From small molecules to Peptide inhibitors. Cancers (Basel) 7: 179-237, 2015.

36. Raucher D and Ryu JS: Cell-penetrating peptides: Strategies for anticancer treatment. Trends Mol Med 21: 560-570, 2015.

37. Li J, Tan S, Chen X, Zhang CY and Zhang Y: Peptide aptamers with biological and therapeutic applications. Curr Med Chem 18: 4215-4222, 2011.

38. Fuertes MA, Castilla J, Alonso C and Perez JM: Cisplatin biochemical mechanism of action: from cytotoxicity to induction of cell death through interconnections between apoptotic and necrotic pathways. Curr Med Chem 10: 257-266, 2003.

39. Horwitz SB: Taxol (paclitaxel): Mechanisms of action. Ann Oncol (5 Suppl 6): S3-S6, 1994.

40. Huang Y, Li X, Sha H, Zhang L, Bian X, Han X and Liu B: Tumor-penetrating peptide fused to a pro-apoptotic peptide facilitates effective gastric cancer therapy. Oncol Rep 37: 2063-2070, 2017.

41. Zhang B, Shi W, Li J, Liao C, Yang L, Huang W and Qian H: Synthesis and biological evaluation of novel peptides based on antimicrobial peptides as potential agents with antitumor and multidrug resistance-reversing activities. Chem Biol Drug Des 90: 972-980, 2017.

42. Ramsey JD and Flynn NH: Cell-penetrating peptides transport therapeutics into cells. Pharmacol Ther 154: 78-86, 2015.

43. Kapoor P, Singh H, Gautam A, Chaudhary K, Kumar R and Raghava GP: TumorHoPe: A database of tumor homing peptides. PLoS One 7: e35187, 2012.

44. Ghasemy S, Garcia-Pindado J, Aboutalebi F, Dormiani K, Teixido M and Malakoutikhah M: Fine-tuning the physicochemical properties of peptide-based blood-brain barrier shuttles. Bioorg Med Chem 26: 2099-2106, 2018.

45. Buckton LK and McAlpine SR: Improving the cell permeability of polar cyclic peptides by replacing residues with alkylated amino acids, asparagines, and d-Amino Acids. Org Lett 20 506-509, 2018

46. Perry SR, Hill TA, de Araujo AD, Hoang HN and Fairlie DP: Contiguous hydrophobic and charged surface patches in short helix-constrained peptides drive cell permeability. Org Biomol Chem 16: 367-371, 2018.

47. Shoombuatong $\mathrm{W}$, Schaduangrat $\mathrm{N}$ and Nantasenamat $\mathrm{C}$ : Unraveling the bioactivity of anticancer peptides as deduced from machine learning. EXCLI J 17: 734-752, 2018.

48. Dai YX, Cai XG, Shi W, Bi XZ, Su X, Pan MB, Li HL, Lin HY, Huang WL and Qian H: Pro-apoptotic cationic host defense peptides rich in lysine or arginine to reverse drug resistance by disrupting tumor cell membrane. Amino Acids 49: 1601-1610, 2017
49. Navarro S, Aleu J, Jimenez M, Boix E, Cuchillo CM and Nogues MV: The cytotoxicity of eosinophil cationic protein/ribonuclease 3 on eukaryotic cell lines takes place through its aggregation on the cell membrane. Cell Mol Life Sci 65: 324-337, 2008.

50. Midoux P, Kichler A, Boutin V, Maurizot JC and Monsigny M: Membrane permeabilization and efficient gene transfer by a peptide containing several histidines. Bioconjug Chem 9: 260-267, 1998.

51. Yamaguchi Y, Yamamoto K, Sato Y, Inoue S, Morinaga T and Hirano E: Combination of aspartic acid and glutamic acid inhibits tumor cell proliferation. Biomed Res 37: 153-159, 2016.

52. Oancea E, Teruel MN, Quest AF and Meyer T: Green fluorescent protein (GFP)-tagged cysteine-rich domains from protein kinase $\mathrm{C}$ as fluorescent indicators for diacylglycerol signaling in living cells. J Cell Biol 140: 485-498, 1998.

53. Shamova O, Orlov D, Stegemann C, Czihal P, Hoffmann R, Brogden K, Kolodkin N, Sakuta G, Tossi A, Sahl HG, et al: ChBac3.4: A Novel proline-rich antimicrobial peptide from goat leukocytes. Int J Pept Res Ther 15: 107-119, 2009.

54. Maddocks ODK, Athineos D, Cheung EC, Lee P, Zhang T, van den Broek NJF, Mackay GM, Labuschagne CF, Gay D, Kruiswijk F, et al: Modulating the therapeutic response of tumours to dietary serine and glycine starvation. Nature 544: 372-376, 2017.

55. Kawaguchi K, Han Q, Li S, Tan Y, Igarashi K, Kiyuna T, Miyake K, Miyake M, Chmielowski B, Nelson SD, et al: Targeting methionine with oral recombinant methioninase (o-rMETase) arrests a patient-derived orthotopic xenograft (PDOX) model of BRAF-V600E mutant melanoma: Implications for chronic clinical cancer therapy and prevention. Cell Cycle 17: 356-361, 2018.

56. Gueron G, Anselmino N, Chiarella P, Ortiz EG, Lage Vickers S, Paez AV, Giudice J, Contin MD, Leonardi D, Jaworski F, et al: Game-changing restraint of Ros-damaged phenylalanine, upon tumor metastasis. Cell Death Dis 9: 140, 2018.

57. Dennison SR, Whittaker M, Harris F and Phoenix DA: Anticancer alpha-helical peptides and structure/function relationships underpinning their interactions with tumour cell membranes. Curr Protein Pept Sci 7: 487-499, 2006.

58. Marchand C, Krajewski K, Lee HF, Antony S, Johnson AA, Amin R, Roller P, Kvaratskhelia M and Pommier Y: Covalent binding of the natural antimicrobial peptide indolicidin to DNA abasic sites. Nucleic Acids Res 34: 5157-5165, 2006.

59. Barras D, Chevalier N, Zoete V, Dempsey R, Lapouge K, Olayioye MA, Michielin O and Widmann C: A WXW motif is required for the anticancer activity of the TAT-RasGAP317-326 peptide. J Biol Chem 289: 23701-23711, 2014.

60. Ahmaditaba MA, Shahosseini S, Daraei B, Zarghi A and Houshdar Tehrani MH: Design, synthesis, and biological evaluation of new peptide analogues as selective cox-2 inhibitors. Arch Pharm (Weinheim) 350: e1700158, 2017.

61. Bhunia D, Mondal P, Das G, Saha A, Sengupta P, Jana J, Mohapatra S, Chatterjee S and Ghosh S: Spatial position regulates power of tryptophan: Discovery of a major-groove-specific nuclear-localizing, cell-penetrating tetrapeptide. J Am Chem Soc 140: 1697-1714, 2018.

62. Huang YB, Wang XF, Wang HY, Liu Y and Chen Y: Studies on mechanism of action of anticancer peptides by modulation of hydrophobicity within a defined structural framework. Mol Cancer Ther 10: 416-426, 2011.

63. Yang QZ, Wang C, Lang L, Zhou Y, Wang H and Shang DJ: Design of potent, non-toxic anticancer peptides based on the structure of the antimicrobial peptide, temporin-1CEa. Arch Pharm Res 36: 1302-1310, 2013.

64. Dennison SR, Harris F, Bhatt T, Singh J and Phoenix DA: A theoretical analysis of secondary structural characteristics of anticancer peptides. Mol Cell Biochem 333: 129-135, 2010.

65. Wu JM, Jan PS, Yu HC, Haung HY, Fang HJ, Chang YI, Cheng JW and Chen HM: Structure and function of a custom anticancer peptide, CB1a. Peptides 30: 839-848, 2009.

66. Lins L and Brasseur R: Tilted peptides: A structural motif involved in protein membrane insertion? J Pept Sci 14: 416-422, 2008.

67. Lins L, Decaffmeyer M, Thomas A and Brasseur R: Relationships between the orientation and the structural properties of peptides and their membrane interactions. Biochim Biophys Acta 1778: 1537-1544, 2008.

68. Mandal PK, Gao F, Lu Z, Ren Z, Ramesh R, Birtwistle JS, Kaluarachchi KK, Chen X, Bast RC Jr, Liao WS, et al: Potent and selective phosphopeptide mimetic prodrugs targeted to the Src homology 2 (SH2) domain of signal transducer and activator of transcription 3. J Med Chem 54: 3549-3563, 2011. 
69. Gabernet G, Gautschi D, Muller AT, Neuhaus CS, Armbrecht L, Dittrich PS, Hiss JA and Schneider G: In silico design and optimization of selective membranolytic anticancer peptides. Sci Rep 9: 11282, 2019

70. Singh M, Kumar V, Sikka K, Thakur R, Harioudh MK, Mishra DP, Ghosh JK and Siddiqi MI: Computational design of biologically active anticancer peptides and their interactions with heterogeneous POPC/POPS Lipid membranes. J Chem Inf Model 60: 332-341, 2020.

71. Ray T, Kar D, Pal A, Mukherjee S, Das C and Pal A: Molecular targeting of breast and colon cancer cells by PAR 1 mediated apoptosis through a novel pro-apoptotic peptide. Apoptosis 23 679-694, 2018.

72. Bohmova E, Machova D, Pechar M, Pola R, Venclikova K, Janouskova O and Etrych T: Cell-penetrating peptides: A usefu tool for the delivery of various cargoes into cells. Physiol Res 67 (Suppl 2): S267-S279, 2018.

73. Levely ME, Mitchell MA and Nicholas JA: Synthetic immunogens constructed from T-cell and B-cell stimulating peptides (T:B chimeras): Preferential stimulation of unique T- and B-cell specificities is influenced by immunogen configuration. Cell Immunol 125: 65-78, 1990 .

74. Asao T, Takahashi F and Takahashi K: Resistance to molecularly targeted therapy in non-small-cell lung cancer. Respir Investig 57: 20-26, 2019.

75. Zhang H, Han D, Lv T, Liu K, Yang Y, Xu X and Chen Y: Novel peptide myristoly-CM4 induces selective cytotoxicity in leukemia K562/MDR and Jurkat cells by necrosis and/or apoptosis pathway. Drug Des Devel Ther 13: 2153-2167, 2019.

76. Chen YQ, Min C, Sang M, Han YY, Ma X, Xue XQ and Zhang SQ: A cationic amphiphilic peptide ABP-CM4 exhibits selective cytotoxicity against leukemia cells. Peptides 31 1504-1510, 2010.

77. Jiang R, Du X and Lonnerdal B: Comparison of bioactivities of talactoferrin and lactoferrins from human and bovine milk J Pediatr Gastroenterol Nutr 59: 642-652, 2014.

78. Tyagi A, Kapoor P, Kumar R, Chaudhary K, Gautam A and Raghava GP: In silico models for designing and discovering novel anticancer peptides. Sci Rep 3: 2984, 2013.

79. Hajisharifi Z, Piryaiee M, Mohammad Beigi M, Behbahani M and Mohabatkar H: Predicting anticancer peptides with Chou's pseudo amino acid composition and investigating their mutagenicity via Ames test. J Theor Biol 341: 34-40, 2014.

80. Chen W, Feng PM, Lin H and Chou KC: iRSpot-PseDNC: Identify recombination spots with pseudo dinucleotide composition. Nucleic Acids Res 41: e68, 2013.

81. Grisoni F, Neuhaus C, Gabernet G, Muller A, Hiss J and Schneider G: Designing anticancer peptides by constructive machine learning. ChemMedChem 13: 1300-1302, 2018.

82. Kozlowska K, Nowak J, Kwiatkowski B and Cichorek M: ESR study of plasmatic membrane of the transplantable melanoma cells in relation to their biological properties. Exp Toxicol Pathol 51: 89-92, 1999.

83. Mai JC, Mi Z, Kim SH, Ng B and Robbins PD: A proapoptotic peptide for the treatment of solid tumors. Cancer Res 61 7709-7712, 2001.

84.Zhang W, Li J, Liu LW, Wang KR, Song JJ, Yan JX, Li ZY, Zhang BZ and Wang R: A novel analog of antimicrobial peptide Polybia-MPI, with thioamide bond substitution, exhibits increased therapeutic efficacy against cancer and diminished toxicity in mice. Peptides 31: 1832-1838, 2010.

85. Sinthuvanich C, Veiga AS, Gupta K, Gaspar D, Blumenthal R and Schneider JP: Anticancer $\beta$-hairpin peptides: Membraneinduced folding triggers activity. J Am Chem Soc 134 6210-6217, 2012

86. Gaspar D, Veiga AS, Sinthuvanich C, Schneider JP and Castanho MA: Anticancer peptide SVS-1: Efficacy precedes membrane neutralization. Biochemistry 51: 6263-6265, 2012.

87. Negi B, Kumar D and Rawat DS: Marine peptides as anticancer agents: A remedy to mankind by nature. Curr Protein Pept Sci 18: 885-904, 2017

88. Lemeshko VV: Electrical potentiation of the membrane permeabilization by new peptides with anticancer properties. Biochim Biophys Acta 1828: 1047-1056, 2013.

89. Liu X, Cao R, Wang S, Jia J and Fei H: Amphipathicity determines different cytotoxic mechanisms of lysine- or arginine-rich cationic hydrophobic peptides in cancer cells. J Med Chem 59 5238-5247, 2016.

90. Hu C, Chen X, Zhao W, Chen Y and Huang Y: Design and modification of anticancer peptides. Drug Des 5: 1000138-1000147, 2016.
91. Boohaker RJ, Lee MW, Vishnubhotla P, Perez JM and Khaled AR: The use of therapeutic peptides to target and to kill cancer cells. Curr Med Chem 19: 3794-3804, 2012.

92. Bidwell GL III and Raucher D: Therapeutic peptides for cancer therapy. Part I-peptide inhibitors of signal transduction cascades. Expert Opin Drug Deliv 6: 1033-1047, 2009.

93. Raucher D, Moktan S, Massodi I and Bidwell GL III: Therapeutic peptides for cancer therapy. Part II-cell cycle inhibitory peptides and apoptosis-inducing peptides. Expert Opin Drug Deliv 6: 1049-1064, 2009.

94. Ulasov IV, Borovjagin AV, Timashev P, Cristofanili M and Welch DR: KISS1 in breast cancer progression and autophagy. Cancer Metastasis Rev 38: 493-506, 2019.

95. Lamidi OF, Sani M, Lazzari P, Zanda M and Fleming IN The tubulysin analogue KEMTUB10 induces apoptosis in breast cancer cells via p53, Bim and Bcl-2. J Cancer Res Clin Oncol 141: 1575-1583, 2015.

96. Wang C, Chen YW, Zhang L, Gong XG, Zhou Y and Shang DJ: Melanoma cell surface-expressed phosphatidylserine as a therapeutic target for cationic anticancer peptide, temporin-1CEa J Drug Target 24: 548-556, 2016.

97. Cao XW, Yang XZ, Du X, Fu LY, Zhang TZ, Shan HW, Zhao J and Wang FJ: Structure optimisation to improve the delivery efficiency and cell selectivity of a tumour-targeting cell-penetrating peptide. J Drug Target 26: 777-792, 2018

98. Shull AY, Hu CA and Teng Y: Zebrafish as a model to evaluate peptide-related cancer therapies. Amino Acids 49: 1907-1913, 2017

99. Leite ML, da Cunha NB and Costa FF: Antimicrobial peptides, nanotechnology, and natural metabolites as novel approaches for cancer treatment. Pharmacol Ther 183: 160-176, 2018.

100. Sun T, Zhang YS, Pang B, Hyun DC, Yang M and Xia Y: Engineered nanoparticles for drug delivery in cancer therapy. Angew Chem Int Ed Engl 53: 12320-12364, 2014.

101. Dossa F, Acuna SA, Rickles AS, Berho M, Wexner SD, Quereshy FA, Baxter NN and Chadi SA: Association between adjuvant chemotherapy and overall survival in patients with rectal cancer and pathological complete response after neoadjuvant chemotherapy and resection. JAMA Oncol 4: 930-937, 2018

102. Xu J, Khan AR, Fu M, Wang R, Ji J and Zhai G: Cell-penetrating peptide: A means of breaking through the physiological barriers of different tissues and organs. J Control Release 309: 106-124, 2019.

103. Duarte D, Fraga AG, Pedrosa J, Martel F and Vale N: Increasing the potential of cell-penetrating peptides for cancer therapy using a new pentagonal scaffold. Eur J Pharmacol 860: 172554, 2019.

104. Park SE, Sajid MI, Parang K and Tiwari RK: Cyclic cell-penetrating peptides as efficient intracellular drug delivery tools. Mol Pharm 16: 3727-3743, 2019.

105. Copolovici DM, Langel K, Eriste E and Langel U: Cell-penetrating peptides:Design, synthesis, and applications ACS Nano 8: 1972-1994, 2014

106. Rothbard JB, Jessop TC, Lewis RS, Murray BA and Wender PA Role of membrane potential and hydrogen bonding in the mechanism of translocation of guanidinium-rich peptides into cells. J Am Chem Soc 126: 9506-9507, 2004.

107. Guidotti G, Brambilla L and Rossi D: Cell-penetrating peptides: From basic research to clinics. Trends Pharmacol Sci 38 406-424, 2017

108. Pujals S and Giralt E: Proline-rich, amphipathic cell-penetrating peptides. Adv Drug Deliv Rev 60: 473-484, 2008

109. Marks JR, Placone J, Hristova K and Wimley WC: Spontaneous membrane-translocating peptides by orthogonal high-throughput screening. J Am Chem Soc 133: 8995-9004, 2011.

110. Koren E and Torchilin VP: Cell-penetrating peptides: Breaking through to the other side. Trends Mol Med 18: 385-393, 2012.

111. Kamei N, Onuki Y, Takayama K and Takeda-Morishita M: Mechanistic study of the uptake/permeation of cell-penetrating peptides across a caco-2 monolayer and their stimulatory effect on epithelial insulin transport. J Pharm Sci 102: 3998-4008, 2013.

112. Chen Y, Xie X, Wu A, Wang L, Hu Y, Zhang H and Li Y: A synthetic cell-penetrating peptide derived from nuclear localization signal of EPS8 exerts anticancer activity against acute myeloid leukemia. J Exp Clin Cancer Res 37: 12, 2018.

113. Lyu L, Huang LQ, Huang T, Xiang W, Yuan JD and Zhang CH: Cell-penetrating peptide conjugates of gambogic acid enhance the antitumor effect on human bladder cancer EJ cells through ROS-mediated apoptosis. Drug Des Devel Ther 12: 743-756, 2018. 
114. Benergossi J, Calixto G, Fonseca-Santos B, Aida KL, de Cassia Negrini T, Duque C, Gremiao MP and Chorilli M: Highlights in peptide nanoparticle carriers intended to oral diseases. Curr Top Med Chem 15: 345-355, 2015.

115. Meng F, Han N and Yeo Y: Organic nanoparticle systems for spatiotemporal control of multimodal chemotherapy. Expert Opin Drug Deliv 14: 427-446, 2017.

116. Conibear AC, Schmid A, Kamalov M, Becker CFW and Bello C: Recent advances in peptide-based approaches for cancer treatment. Curr Med Chem 27: 1174-1205, 2017.

117. Asadzadeh Z, Mohammadi H, Safarzadeh E, Hemmatzadeh M, Mahdian-Shakib A, Jadidi-Niaragh F, Azizi G and Baradaran B: The paradox of Th17 cell functions in tumor immunity. Cell Immunol 322: 15-25, 2017

118. Darabi A, Thuring C and Paulsson KM: HLA-I antigen presentation and tapasin influence immune responses against malignant brain tumors-considerations for successful immunotherapy. Anticancer Agents Med Chem 14: 1094-1100, 2014

119. Li M, Shi HS, Zhang HL, Luo ZC, Wan Y, Lu L, Luo ST and Yang L: bFGF peptide combined with the pVAX-8CpG plasmid as adjuvant is a novel anticancer vaccine inducing effective immune responses against Lewis lung carcinoma. Mol Med Rep 5: 625-630, 2012.

120.Wang W, Li Y, Wang Y, Ren S, Li Y and Wang B: Polyactin $\mathrm{A}$ is a novel and potent immunological adjuvant for peptidebased cancer vaccine. Int Immunopharmacol 54: 95-102, 2018

121. Jin H, Wan C, Zou Z, Zhao G, Zhang L, Geng Y, Chen T, Huang A, Jiang F, Feng JP, et al: Tumor ablation and therapeutic immunity induction by an injectable peptide hydrogel. ACS Nano 12: 3295-3310, 2018.

122. Kakwere H, Ingham ES, Allen R, Mahakian LM, Tam SM, Zhang H, Silvestrini MT, Lewis JS and Ferrara KW: Toward personalized peptide-based cancer nanovaccines: A facile and versatile synthetic approach. Bioconjug Chem 28: 2756-2771, 2017.

123. Apostolopoulos V and McKenzie IF: Cellular mucins: Targets for immunotherapy. Crit Rev Immunol 14: 293-309, 1994.

124. Obara W, Eto M, Mimata H, Kohri K, Mitsuhata N, Miura I, Shuin T, Miki T, Koie T, Fujimoto H, et al: A phase I/II study of cancer peptide vaccine S-288310 in patients with advanced urothelial carcinoma of the bladder. Ann Oncol 28: 798-803, 2017.

125. Antonilli M, Rahimi H, Visconti V, Napoletano C, Ruscito I, Zizzari IG, Caponnetto S, Barchiesi G, Iadarola R, Pierelli L, et al: Triple peptide vaccination as consolidation treatment in women affected by ovarian and breast cancer: Clinical and immunological data of a phase I/II clinical trial. Int J Oncol 48: 1369-1378, 2016.

126. Asahara S, Takeda K, Yamao K, Maguchi $\mathrm{H}$ and Yamaue $\mathrm{H}$ : Phase I/II clinical trial using HLA-A24-restricted peptide vaccine derived from KIF20A for patients with advanced pancreatic cancer. J Transl Med 11: 291, 2013.

127. Rausch S, Gouttefangeas C, Hennenlotter J, Laske K, Walter K, Feyerabend S, Chandran PA, Kruck S, Singh-Jasuja H, Frick A, et al: Results of a Phase 1/2 Study in Metastatic Renal Cell Carcinoma Patients Treated with a Patient-specific Adjuvant Multi-peptide Vaccine after Resection of Metastases. Eur Urol Focus 5: 604-607, 2019.

128. Dutoit V, Migliorini D, Ranzanici G, Marinari E, Widmer V, Lobrinus JA, Momjian S, Costello J, Walker PR, Okada H, et al: Antigenic expression and spontaneous immune responses support the use of a selected peptide set from the IMA950 glioblastoma vaccine for immunotherapy of grade II and III glioma. Oncoimmunology 7: e1391972, 2018

129. Lilleby W, Gaudernack G, Brunsvig PF, Vlatkovic L, Schulz M, Mills K, Hole KH and Inderberg EM: Phase I/IIa clinical trial of a novel hTERT peptide vaccine in men with metastatic hormone-naive prostate cancer. Cancer Immunol Immunother 66: 891-901, 2017.

130. Talebi S, Bolhassani A, Azad TM, Arashkia A and Modaresi MH Immuno-stimulating peptide derived from HMGB1 is more effective than the $\mathrm{N}$-terminal domain of $\mathrm{Gp} 96$ as an endogenous adjuvant for improvement of protein vaccines. Protein Pept Lett 24: 190-196, 2017.

131. Glover S, Delaney M, Dematte C, Kornberg L, Frasco M, Tran-Son-Tay R and Benya RV: Phosphorylation of focal adhesion kinase tyrosine 397 critically mediates gastrin-releasing peptide's morphogenic properties. J Cell Physiol 199: 77-88, 2004.
132. Schally AV, Zhang X, Cai R, Hare JM, Granata R and Bartoli M: Actions and potential therapeutic applications of growth hormone-releasing hormone agonists. Endocrinology 160: 1600-1612, 2019.

133. Munoz-Moreno L, Bajo AM, Prieto JC and Carmena MJ: Growth hormone-releasing hormone $(\mathrm{GHRH})$ promotes metastatic phenotypes through EGFR/HER2 transactivation in prostate cancer cells. Mol Cell Endocrinol 446: 59-69, 2017.

134. Jimenez JJ, DelCanto GM, Popovics P, Perez A, Vila Granda A, Vidaurre I, Cai RZ, Rick FG, Swords RT and Schally AV: A new approach to the treatment of acute myeloid leukaemia targeting the receptor for growth hormone-releasing hormone. Br J Haematol 181: 476-485, 2018.

135. Chin YT, Wang LM, Hsieh MT, Shih YJ, Nana AW, Changou CA, Yang YSH, Chiu HC, Fu E, Davis PJ, et al: Leptin OB3 peptide suppresses leptin-induced signaling and progression in ovarian cancer cells. J Biomed Sci 24: 51, 2017.

136. Zhang M, Zhang M, Wang J, Cai Q, Zhao R, Yu Y, Tai H, Zhang $\mathrm{X}$ and $\mathrm{Xu} \mathrm{C}$ : Retro-inverso follicle-stimulating hormone peptide-mediated polyethylenimine complexes for targeted ovarian cancer gene therapy. Drug Deliv 25: 995-1003, 2018.

137. Sogaard CK, Moestue SA, Rye MB, Kim J, Nepal A,Liabakk NB, Bachke S, Bathen TF, Otterlei M and Hill DK: APIM-peptide targeting PCNA improves the efficacy of docetaxel treatment in the TRAMP mouse model of prostate cancer. Oncotarget 9: 11752-11766, 2018.

138. Farokhzad OC and Langer R: Impact of nanotechnology on drug delivery. ACS Nano 3: 16-20, 2009.

139. Liu X, Peng J, He J, Li Q, Zhou J, Liang X and Tang S: Selection and identification of novel peptides specifically targeting human cervical cancer. Amino Acids 50: 577-592, 2018.

140. Serrill JD, Wan X, Hau AM, Jang HS, Coleman DJ, Indra AK, Alani AW, McPhail KL and Ishmael JE: Coibamide A, a natural lariat depsipeptide, inhibits VEGFA/VEGFR2 expression and suppresses tumor growth in glioblastoma xenografts. Invest New Drugs 34: 24-40, 2016.

141. Chakrabarti S, Guha S and Majumder K: Food-derived bioactive peptides in human health: Challenges and opportunities. Nutrients 10: 1738, 2018.

142. Sable R, Parajuli P and Jois S: Peptides, Peptidomimetics, and polypeptides from marine sources: A wealth of natural sources for pharmaceutical applications. Mar Drugs 15: 124, 2017.

143. O'Brien-Simpson NM, Hoffmann R, Chia CSB and Wade JD: Editorial: Antimicrobial and Anticancer Peptides. Front Chem 6: 13, 2018.

144. Sultan S, Huma N, Butt MS, Aleem M and Abbas M: Therapeutic potential of dairy bioactive peptides: A contemporary perspective. Crit Rev Food Sci Nutr 58: 105-115, 2018.

145. Felicio MR, Silva ON, Goncalves S, Santos NC and Franco OL: Peptides with dual antimicrobial and anticancer activities. Front Chem 5: 5, 2017.

146. Mohanty DP, Mohapatra S, Misra S and Sahu PS: Milk derived bioactive peptides and their impact on human health-A review. Saudi J Biol Sci 23: 577-583, 2016.

147. Gonzalez-Montoya M, Hernandez-Ledesma B, Silvan JM, Mora-Escobedo R and Martinez-Villaluenga C: Peptides derived from in vitro gastrointestinal digestion of germinated soybean proteins inhibit human colon cancer cells proliferation and inflammation. Food Chem 242: 75-82, 2018.

148. Prateep A, Sumkhemthong S, Suksomtip M, Chanvorachote P and Chaotham C: Peptides extracted from edible mushroom: Lentinus squarrosulus induces apoptosis in human lung cancer cells. Pharm Biol 55: 1792-1799, 2017.

149. Newman DJ and Cragg GM: Natural products as sources of new drugs over the last 25 years. J Nat Prod 70: 461-477, 2007.

150. Fahs S, Patil-Sen Y and Snape TJ: Foldamers as anticancer therapeutics: Targeting protein-protein interactions and the cell membrane. Chembiochem 16: 1840-1853, 2015.

151. Dhar A, Mallick S, Ghosh P, Maiti A, Ahmed I, Bhattacharya S, Mandal T, Manna A, Roy K, Singh S, et al: Simultaneous inhibition of key growth pathways in melanoma cells and tumor regression by a designed bidentate constrained helical peptide. Biopolymers 102: 344-358, 2014.

152. Tanishiki N, Yano Y and Matsuzaki K: Endowment of $\mathrm{pH}$ responsivity to anticancer peptides by introducing 2,3-diaminopropionic acid residues. Chembiochem 20: 2109-2117, 2019.

153. Dennison SR, Harris F, Mura M and Phoenix DA: An atlas of anionic antimicrobial peptides from amphibians. Curr Protein Pept Sci 19: 823-838, 2018. 
154. Khamessi O, Ben Mabrouk H, ElFessi-Magouri $\mathrm{R}$ and Kharrat R: RK1, the first very short peptide from Buthus occitanus tunetanus inhibits tumor cell migration, proliferation and angiogenesis. Biochem Biophys Res Commun 499: 1-7, 2018.

155. Choi YJ, Park SJ, Park YS, Park HS, Yang KM and Heo K: EpCAM peptide-primed dendritic cell vaccination confers significant anti-tumor immunity in hepatocellular carcinoma cells. PLoS One 13: e0190638, 2018.

156. Matsueda S, Itoh K and Shichijo S: Antitumor activity of antibody against cytotoxic T lymphocyte epitope peptide of lymphocyte-specific protein tyrosine kinase. Cancer Sci 109: 611-617, 2018

157. Peng X, Zhou C, Hou X, Liu Y, Wang Z, Peng X, Zhang Z, Wang R and Kong D: Molecular characterization and bioactivity evaluation of two novel bombinin peptides from the skin secretion of Oriental fire-bellied toad, Bombina orientalis. Amino Acids 50: 241-253, 2018.

158. Xie X, Zhou W, Hu Y, Chen Y, Zhang H and Li Y: A dual-function epidermal growth factor receptor pathway substrate 8 (Eps8)-derived peptide exhibits a potent cytotoxic T lymphocyte-activating effect and a specific inhibitory activity. Cell Death Dis 9: 379, 2018

159. Wu ZZ, Ding GF, Huang FF, Yang ZS, Yu FM, Tang YP, Jia YL, Zheng YY and Chen R: Anticancer activity of anthopleura anjunae oligopeptides in prostate cancer DU-145 cells. Mar Drugs 16: pii: E125, 2018

160. Shen Y, Maupetit J, Derreumaux P and Tuffery P: Improved PEP-FOLD approach for peptide and miniprotein structure prediction. J Chem Theory Comput 10: 4745-4758, 2014.

161. Thevenet P, Shen Y, Maupetit J, Guyon F, Derreumaux P and Tuffery P: PEP-FOLD: An updated de novo structure prediction server for both linear and disulfide bonded cyclic peptides. Nucleic Acids Res 40: W288-W293, 2012.

162. Hao Y, Yang N, Teng D, Wang X, Mao R and Wang J: A review of the design and modification of lactoferricins and their derivatives. Biometals 31: 331-341, 2018.

163. Dathe M, Schumann M, Wieprecht T, Winkler A, Beyermann M, Krause E, Matsuzaki K, Murase O and Bienert M: Peptide helicity and membrane surface charge modulate the balance of electrostatic and hydrophobic interactions with lipid bilayers and biological membranes. Biochemistry 35: 12612-12622, 1996.

164. Sun S, Zhao G, Huang Y, Cai M, Yan Q, Wang H and Chen Y: Enantiomeric effect of d-Amino acid substitution on the mechanism of action of $\alpha$-helical membrane-active peptides. Int J Mol Sci 19: 67, 2017

165. Hicks RP: Antibacterial and anticancer activity of a series of novel peptides incorporating cyclic tetra-substituted $C(\alpha)$ amino acids. Bioorg Med Chem 24: 4056-4065, 2016.

166. Zhou J, Yang X, Zhang W, Wang J, Wei C, Gu F, Lei T and Qin Y: Construction of an Anticancer Fusion Peptide (ACFP) derived from milk proteins and an assay of anti-ovarian cancer cells in vitro. Anticancer Agents Med Chem 17: 635-643, 2017.

167. Bracci L, Mandarini E, Brunetti J, Depau L, Pini A, Terzuoli L, Scali S and Falciani C: The GAG-specific branched peptide NT4 reduces angiogenesis and invasiveness of tumor cells. PLoS One 13: e0194744, 2018.

168. Chu HL, Yip BS, Chen KH, Yu HY, Chih YH, Cheng HT, Chou YT and Cheng JW: Novel antimicrobial peptides with high anticancer activity and selectivity. PLoS One 10: e0126390, 2015 .

169. He B, Yang D, Qin M, Zhang Y, He B, Dai W, Wang X, Zhang Q, Zhang $\mathrm{H}$ and Yin $\mathrm{C}$ : Increased cellular uptake of peptide-modified PEGylated gold nanoparticles. Biochem Biophys Res Commun 494: 339-345, 2017.

170. Tsuchiya N, Hosono A, Yoshikawa T, Shoda K, Nosaka K, Shimomura M, Hara J, Nitani C, Manabe A, Yoshihara H, et al: Phase I study of glypican-3-derived peptide vaccine therapy for patients with refractory pediatric solid tumors. Oncoimmunology 7: e1377872, 2017.

171. Liang AL, Qian HL, Zhang TT, Zhou N, Wang HJ, Men XT, Qi W, Zhang PP, Fu M, Liang X, et al: Bifunctional fused polypeptide inhibits the growth and metastasis of breast cancer Drug Des Devel Ther 9: 5671-5686, 2015.

172. Herbert KJ, Ashton TM, Prevo R, Pirovano G and Higgins GS T-LAK cell-originated protein kinase (TOPK): An emerging target for cancer-specific therapeutics. Cell Death Dis 9: 1089, 2018 .

173. Wu D, Gao Y, Qi Y, Chen L, Ma Y and Li Y: Peptide-based cancer therapy: Opportunity and challenge. Cancer Lett 351: $13-22,2014$
174. Zachos I, Konstantinopoulos PA, Tzortzis V, Gravas S, Karatzas A, Karamouzis MV, Melekos M and Papavassiliou AG: Systemic therapy of metastatic bladder cancer in the molecular era: Current status and future promise. Expert Opin Investig Drugs 19: 875-887, 2010

175. Amir E, Hughes S, Blackhall F, Thatcher N, Ostoros G, Timar J, Tovari J, Kovacs G and Dome B: Targeting blood vessels for the treatment of non-small cell lung cancer. Curr Cancer Drug Targets 8: 392-403, 2008.

176. Kim-Schulze S, Taback B and Kaufman HL: Cytokine therapy for cancer. Surg Oncol Clin N Am 16: 793-818, viii, 2007.

177. Niu F, Yan J, Ma B, Li S, Shao Y, He P, Zhang W, He W, $\mathrm{Ma} P X$ and $\mathrm{Lu} \mathrm{W}$ : Lanthanide-doped nanoparticles conjugated with an anti-CD33 antibody and a p53-activating peptide for acute myeloid leukemia therapy. Biomaterials 167: 132-142, 2018.

178. Vats K, Sharma R, Sarma HD, Satpati D and Dash A: ${ }^{68} \mathrm{Ga}$-labeled HBED-CC variant of uPAR targeting peptide AE105 compared with 68Ga-NODAGA-AE105. Anticancer Agents Med Chem 18: 1289-1294, 2018.

179. Ahmadpour S, Noaparast Z, Abedi SM and Hosseinimehr SJ: 99mTc-(tricine)-HYNIC-Lys-FROP peptide for breast tumor targeting. Anticancer Agents Med Chem 18: 1295-1302, 2018.

180. Zhang J, Spring H and Schwab M: Neuroblastoma tumor cell-binding peptides identified through random peptide phage display. Cancer Lett 171: 153-164, 2001.

181. Soudy R,Etayash H, Bahadorani K,Lavasanifar A and Kaur K: Breast cancer targeting peptide binds keratin 1: A new molecular marker for targeted drug delivery to breast cancer. Mol Pharm 14: 593-604, 2017.

182. Du Y, Wang L, Wang W, Guo T, Zhang M, Zhang P, Zhang Y, Wu K, Li A, Wang X, et al: Novel application of cell penetrating R11 peptide for diagnosis of bladder cancer. J Biomed Nanotechnol 14: 161-167, 2018.

183. Sato S, Nakamura T, Katagiri T, Tsuchikawa T, Kushibiki T, Hontani K, Takahashi M,InokoK, TakanoH,Abe H, et al: Molecular targeting of cell-permeable peptide inhibits pancreatic ductal adenocarcinoma cell proliferation. Oncotarget 8: 113662-113672, 2017.

184. Kang T, Huang Y, Zhu Q, Cheng H, Pei Y, Feng J, Xu M, Jiang G, Song Q, Jiang T, et al: Necroptotic cancer cells-mimicry nanovaccine boosts anti-tumor immunity with tailored immune-stimulatory modality. Biomaterials 164: 80-97, 2018.

185. Garay H, Espinosa LA, Perera Y, Sanchez A, Diago D, Perea SE, Besada V, Reyes O and Gonzalez LJ: Characterization of low-abundance species in the active pharmaceutical ingredient of CIGB-300: A clinical-grade anticancer synthetic peptide. J Pept Sci 24: e3081, 2018.

186. Perea SE, Reyes O, Baladron I, Perera Y, Farina H, Gil J, Rodriguez A, Bacardi D, Marcelo JL, Cosme K, et al: CIGB-300, a novel proapoptotic peptide that impairs the CK2 phosphorylation and exhibits anticancer properties both in vitro and in vivo. Mol Cell Biochem 316: 163-167, 2008.

187. Rodriguez-Ulloa A, Ramos Y, Gil J, Perera Y, Castellanos-Serra L, Garcia Y, Betancourt L, Besada V, Gonzalez LJ, Fernandez-de-Cossio J, et al: Proteomic profile regulated by the anticancer peptide CIGB-300 in non-small cell lung cancer (NSCLC) cells. J Proteome Res 9: 5473-5483, 2010

188. Hirabayashi K, Yanagisawa R, Saito S, Higuchi Y, Koya T, Sano K, Koido S, Okamoto M, Sugiyama H, Nakazawa Y, et al: Feasibility and immune response of WT1 peptide vaccination in combination with OK-432 for paediatric solid tumors Anticancer Res 38: 2227-2234, 2018.

189. Yanagisawa R, Koizumi T, Koya T, Sano K, Koido S, Nagai K, Kobayashi M, Okamoto M, Sugiyama $\mathrm{H}$ and Shimodaira S: WT1-pulsed dendritic cell vaccine combined with chemotherapy for resected pancreatic cancer in a phase I study. Anticancer Res 38: 2217-2225, 2018

190. Ohno S, Takano F, Ohta Y, Kyo S, Myojo S, Dohi S, Sugiyama H, Ohta $\mathrm{T}$ and Inoue M: Frequency of myeloid dendritic cells can predict the efficacy of Wilms' tumor 1 peptide vaccination. Anticancer Res 31: 2447-2452, 2011.

191. Ohno S, Kyo S, Myojo S, Dohi S, Ishizaki J, Miyamoto K, Morita S, Sakamoto J, Enomoto T, Kimura T, et al: Wilms' tumor 1 (WT1) peptide immunotherapy for gynecological malignancy. Anticancer Res 29: 4779-4784, 2009.

192. Ishikawa H, Imano M, Shiraishi O, Yasuda A, Peng YF, Shinkai M, Yasuda T, Imamoto H and Shiozaki H: Phase I clinical trial of vaccination with LY6K-derived peptide in patients with advanced gastric cancer. Gastric Cancer 17: 173-180, 2014.

193. Vasef MA, Ross JS and Cohen MB: Telomerase activity in human solid tumors. Diagnostic utility and clinical applications. Am J Clin Pathol 112 (1 Suppl): S68-S75, 1999. 
194. Bernhardt SL, Gjertsen MK, Trachsel S, Moller M, Eriksen JA, Meo M, Buanes T and Gaudernack G: Telomerase peptide vaccination of patients with non-resectable pancreatic cancer: A dose escalating phase I/II study. Br J Cancer 95: 1474-1482, 2006.

195. Kokhaei P, Palma M, Hansson L, Osterborg A, Mellstedt H and Choudhury A: Telomerase (hTERT 611-626) serves as a tumor antigen in B-cell chronic lymphocytic leukemia and generates spontaneously antileukemic, cytotoxic T cells. Exp Hematol 35 297-304, 2007.

196. Aspeslagh S, Awada A, Matos-Pita A, Aftimos P, Bahleda R, Varga A and Soria JC: Phase I dose-escalation study of plitidepsin in combination with bevacizumab in patients with refractory solid tumors. Anticancer Drugs 27: 1021-1027, 2016.

197. Engel JB, Tinneberg HR, Rick FG, Berkes E and Schally AV Targeting of peptide cytotoxins to LHRH receptors for treatment of cancer. Curr Drug Targets 17: 488-494, 2016.

198. Noguchi M, Matsumoto K, Uemura H, Arai G, Eto M, Naito S, Ohyama C, Nasu Y, Tanaka M, Moriya F, et al: An open-label, randomized phase II trial of personalized peptide vaccination in patients with bladder cancer that progressed after platinum-based chemotherapy. Clin Cancer Res 22: 54-60, 2016.

199. Toh U, Saku S, Okabe M, Iwakuma N, Kimitsuki Y, Akashi M, Ogo E, Yamada A, Shichijo S, Itoh K, et al: Development of peptide vaccines for triple-negative breast cancer treatment. Gan To Kagaku Ryoho 43: 1249-1251, 2016 (In Japanese).

200. Brown TA, Byrd K, Vreeland TJ, Clifton GT, Jackson DO, Hale DF, Herbert GS, Myers JW, Greene JM, Berry JS, et al: Final analysis of a phase I/IIa trial of the folate-binding protein-derived E39 peptide vaccine to prevent recurrence in ovarian and endometrial cancer patients. Cancer Med 8: 4678-4687, 2019.

201. Schwartzentruber DJ, Lawson DH, Richards JM, Conry RM, Miller DM, Treisman J, Gailani F, Riley L, Conlon K, Pockaj B, et al: gp100 peptide vaccine and interleukin-2 in patients with advanced melanoma. N Engl J Med 364: 2119-2127, 2011.

202. Mikecin AM, Walker LR, Kuna M and Raucher D: Thermally targeted p21 peptide enhances bortezomib cytotoxicity in androgen-independent prostate cancer cell lines. Anticancer Drugs 25: 189-199, 2014

203. Korani M, Korani S, Zendehdel E, Nikpoor AR, Jaafari MR, Orafai HM, Johnston TP and Sahebkar A: Enhancing the therapeutic efficacy of bortezomib in cancer therapy using polymeric nanostructures. Curr Pharm Des 25: 4883-4892, 2019.

204.Zhou Y, Liu X, Xue J, Liu L, Liang T, Li W, Yang X, Hou X and Fang H: Discovery of peptide boronate derivatives as histone deacetylase and proteasome dual inhibitors for overcoming bortezomib resistance of multiple myeloma. J Med Chem 63 : 4701-4715, 2020.

205. Garofalo M, Grazioso G, Cavalli A and Sgrignani J: How computational chemistry and drug delivery techniques can support the development of new anticancer drugs. Molecules 25 $1756,2020$.

206. Adlakha S, Sharma A, Vaghasiya K, Ray E and Verma RK: Inhalation delivery of host defence peptides (HDP) using nano-formulation strategies: A pragmatic approach for therapy of pulmonary ailments. Curr Protein Pept Sci 21: 369-378, 2020
207. Tu Y, Tao J, Wang F, Liu P, Han Z, Li Z, Ma Y and Gu Y: A novel peptide targeting gastrin releasing peptide receptor for pancreatic neoplasm detection. Biomater Sci 8: 2682-2693, 2020.

208. Ohana J, Sandler U, Kass G, Stemmer SM and Devary Y: dTCApFs, a derivative of a novel human hormone peptide, induces apoptosis in cancer cells through a mechanism involving loss of Golgi function. Mol Clin Oncol 7: 991-999, 2017.

209. Stemmer SM, Benjaminov O, Silverman MH, Sandler U, Purim O, Sender N, Meir C, Oren-Apoteker P, Ohana J and Devary Y: A phase I clinical trial of dTCApFs, a derivative of a novel human hormone peptide, for the treatment of advanced/metastatic solid tumors. Mol Clin Oncol 8: 22-29, 2018.

210. Murali R and Kieber-Emmons T: Cancer immunotherapeutics: Evolution of monoclonal antibodies to peptide immunogens Monoclon Antib Immunodiagn Immunother 33: 179-182, 2014.

211. Tan Z and Zhang S: Past, present, and future of targeting ras for cancer therapies. Mini Rev Med Chem 16: 345-357, 2016.

212. Li QX, Yu DH, Liu G, Ke N, McKelvy J and Wong-Staal F: Selective anticancer strategies via intervention of the death pathways relevant to cell transformation. Cell Death Differ 15 1197-1210, 2008.

213. Micale N, Scarbaci K, Troiano V, Ettari R, Grasso S and Zappala M: Peptide-based proteasome inhibitors in anticancer drug design. Med Res Rev 34: 1001-1069, 2014.

214. Wang X, Chen X, Yang X, Gao W, He B, Dai W, Zhang H, Wang $X$, Wang J, Zhang $X$, et al: A nanomedicine based combination therapy based on QLPVM peptide functionalized liposomal tamoxifen and doxorubicin against Luminal A breast cancer. Nanomedicine 12: 387-397, 2016.

215. Cheng T and Zhan X: Pattern recognition for predictive, preventive, and personalized medicine in cancer. EPMA J 8: 51-60, 2017.

216. Vadevoo SMP, Gurung S, Khan F, Haque ME, Gunassekaran GR, Chi L, Permpoon U and Lee B: Peptide-based targeted therapeutics and apoptosis imaging probes for cancer therapy. Arch Pharm Res 42: 150-158, 2019.

217. Sun X, Li Y, Liu T, Li Z, Zhang X and Chen X: Peptide-based imaging agents for cancer detection. Adv Drug Deliv Rev 110-111: 38-51, 2017

218. Ehlerding EB, Sun L, Lan X, Zeng D and Cai W: Dual-targeted molecular imaging of cancer. J Nucl Med 59: 390-395, 2018.

219. Wang Q, Li SB, Zhao YY, Dai DN, Du H, Lin YZ, Ye JC, Zhao J, Xiao W, Mei Y, et al: Identification of a sodium pump $\mathrm{Na}(+) / \mathrm{K}(+)$ ATPase alpha1-targeted peptide for PET imaging of breast cancer. J Control Release 281: 178-188, 2018.

220. Perez SA, von Hofe E, Kallinteris NL, Gritzapis AD, Peoples GE, Papamichail $\mathrm{M}$ and Baxevanis $\mathrm{CN}$ : A new era in anticancer peptide vaccines. Cancer 116: 2071-2080, 2010.

This work is licensed under a Creative Commons Attribution-NonCommercial-NoDerivatives 4.0 International (CC BY-NC-ND 4.0) License. 